This document was prepared in conjunction with work accomplished under Contract No. DE-AC09-96SR18500 with the U. S. Department of Energy.

\title{
DISCLAIMER
}

This report was prepared as an account of work sponsored by an agency of the United States Government. Neither the United States Government nor any agency thereof, nor any of their employees, nor any of their contractors, subcontractors or their employees, makes any warranty, express or implied, or assumes any legal liability or responsibility for the accuracy, completeness, or any third party's use or the results of such use of any information, apparatus, product, or process disclosed, or represents that its use would not infringe privately owned rights. Reference herein to any specific commercial product, process, or service by trade name, trademark, manufacturer, or otherwise, does not necessarily constitute or imply its endorsement, recommendation, or favoring by the United States Government or any agency thereof or its contractors or subcontractors. The views and opinions of authors expressed herein do not necessarily state or reflect those of the United States Government or any agency thereof. 


\title{
Neptunium Valence Chemistry In Anion Exchange Processing
}

\author{
Edward A. Kyser
}

Feb 2003

\author{
Westinghouse Savannah River Company \\ Savannah River Site \\ Aiken, SC 29808
}

Prepared for the U. S. Department of Energy under contract DE-AC09-96SR18500. 
WSRC-TR-2003-00111, Rev 0

\section{Neptunium Valence Chemistry \\ In \\ Anion Exchange \\ Processing}

Edward A. Kyser

Feb 28, 2003

Technical Reviewers

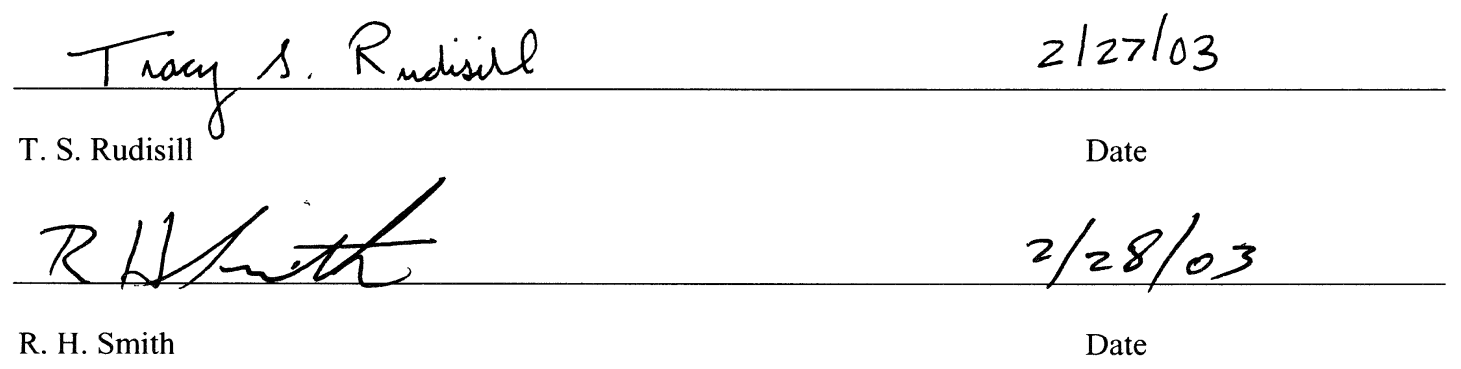




\section{Table of Contents:}

Table of Contents $\quad$ iii

List of Figures $\quad$ iii

List of Tables $\quad$ iii

Acronyms and Terminology

Summary $\quad 5$

$\begin{array}{ll}\text { Background } & 6\end{array}$

Experimental Column Operation $\quad 8$

Process Flowrate Scaling $\quad 8$

Resin Pretreatment 8

$\begin{array}{lr}\text { Column Loading } & 8\end{array}$

Feedstock Preparation and Valence Adjustment 9

Lab Equipment $\quad 9$

Np Loading 10

Reductive Loading/Wash 10

Np Washing and Elution $\quad 11$

$\begin{array}{ll}\text { Analytical } & 11\end{array}$

Calibration of Spectrophotometer $\quad 12$

Results and Discussion $\quad 14$

Resin Loading Losses $\quad 14$

Hydrazine $\quad 15$

Hydrazine in Feed Solution $\quad 15$

Hydrazine in Wash Solution $\quad 16$

Hydrazine in Elution Acid 16

$\begin{array}{ll}\mathrm{Pu} \text { and } \mathrm{Pa} \text { Decontamination } & 18\end{array}$

$\begin{array}{lr}\text { Uncertainties } & 18\end{array}$

$\begin{array}{lr}\text { Conclusions } & 19\end{array}$

References $\quad 21$

List of Figures:

Figure 1. Process Flow Diagram of Anion Exchange Process in HB-Line 6

Figure 2. Column used in Experiments 9

Figure 3. Experimental Setup 9

Figure 4. $\mathrm{Np}^{5+}$ Spectra in Low $\mathrm{HNO}_{3} \quad 11$

Figure 5. $\mathrm{Np}^{4+}$ Spectra in Low and High $\mathrm{HNO}_{3}$ Compared with $\mathrm{Np}^{5+}$ Spectra 11

Figure 6. Oxidation of Diluted Np Hearts over Time 900-1000nm 17

Figure 7. Oxidation of Diluted Np Hearts over Time 580-750nm 17

Figure 8. Oxidation of $\mathrm{Np}^{4+}$ to $\mathrm{Np}^{5+}$ in Weak $\mathrm{HNO}_{3} \quad 18$

List of Tables:

Table I. Comparison of SRTC Conditions to HB-Line Standard Flowsheet 8

Table II. Spectrophotometer System Parts List 10

Table III. Example of Material Balance for a Column Run 13

Table IV. Summary of Loading and Loss Results for Np $\quad 14$

Table V. Oxidation of Np in Anion Feed Solution 15

Table VI. Oxidation of Np in Anion Product Solution 16

Table VII. Summary of Pu and Pa DF Behavior 20 


\section{Acronyms and Terminology:}

FS - Ferrous Sulfamate is the primary reducing agent used to adjust $\mathrm{Pu}$ and $\mathrm{Np}$ valence states in the separation processes.

$\mathrm{N}_{2} \mathrm{H}_{4}$ - Hydrazine: purchased as hydrazine mono-nitrate that is commonly prepared by neutralizing the strongly basic hydrazine mono-hydrate with $\mathrm{HNO}_{3}$.

$\mathrm{HN}_{3}$ - Hydrazoic acid: Reaction product from hydrazine and nitrous acid.

$\mathrm{HNO}_{3}-$ Nitric acid

$\mathrm{HNO}_{2}-$ Nitrous acid

$\mathrm{SO}_{4}{ }^{2-}$ - Sulfate ion: Reaction product from sulfamate in the ferrous sulfamate.

$\mathrm{C}_{2} \mathrm{O}_{4}{ }^{2-}$ - Oxalate: From oxalic acid used to precipitate $\mathrm{Np}$ oxalate

$\mathrm{NaNO}_{3}$ - Sodium nitrate

HLW - (High Level Waste) Liquid waste containing actinides that will be transferred to the tank farm

DSA - Documented Safety Analysis

SRTC ADS or ADS - Analytical Development Section of Savannah River Technology Center: Provided analytical services in support of this work.

$\mathrm{NaI}$ - Sodium Iodide: Type of detector used to measure holdup by gamma rays.

BV- (Bed Volume) Volume occupied by the bed of resin in a column. Includes both resin volume and void space volume.

Linear Velocity - (Q/A): The volumetric flowrate divided by the cross sectional area of a resin column. Reflects the velocity of the solution flowing through a column (ignoring the space occupied by the resin beds).

Q - Volumetric flowrate

A - Cross sectional area of a resin bed in the column

$\mathrm{H}$ - Height of the resin bed in the column

Raffinate - Solution that is discharged from the column after flowing through the resin bed to absorb the Np

Effluent - Solution that is discharged from the column after flowing through the resin bed to either absorb the Np or wash impurities from the bed.

Elution - The process step where dilute acid is passed through the resin bed to remove the absorbed $\mathrm{Np}$ and collect it as a product solution.

Load - The process step where 6-9 $\mathrm{M} \mathrm{HNO}_{3}$ containing $\mathrm{Np}$ is passed through the resin bed to absorb the $\mathrm{Np}$ onto the resin.

Visual Break-through - Point during the loading cycle where $\mathrm{Np}$ can be visually observed in the effluent from the column by its pale green color. Concentration where this occurs in laboratory sized equipment is in the range of 0.2 to $1 \mathrm{~g} \mathrm{~Np} / \mathrm{L}$.

Heads Cut - Initial portion of elution solution that has passed through the column. This solution consists of the displacement of the $8 \mathrm{M} \mathrm{HNO}_{3}$ contained within the resin bed and column from the loading/wash steps and contains minimal $\mathrm{Np}$ at 4 to $6 \mathrm{M} \mathrm{HNO}_{3}$.

Hearts Cut - High concentration product Np solution taken from the middle portion of the elution step. Often will be cut off at the point the Np concentration drops to a low level, but prior to complete elution of the column.

Tails Cut - Last portion of elution step that contains dilute $\mathrm{HNO}_{3}$ and minimal Np. May be generated when excess elution acid is used to ensure complete elution of $\mathrm{Np}$ from the column.

Down-Flow - Refers to the flow direction of the process stream as being the same direction as gravity through the column.

Up-Flow - Refers to the flow direction of the process stream as being the opposite direction as gravity through the column.

Composite Sample - Solution collected for a relatively long period of time. Represents solution collected over a significant portion of a step of the process. Normally used for material balance calculations.

Grab Sample - Sample collected over a relatively short period of time. Approximates an instantaneous sample.

DF - Decontamination Factor: A measure of the ability of the process to remove a specific impurity. Calculated by dividing the concentration of the impurity (on a $\mathrm{Np}$ basis) in the feed solution by the concentration of the impurity in the product solution.

ND - None detected by analytical method.

na - Not available or not applicable. 


\title{
Neptunium Valence Chemistry In Anion Exchange Processing
}

By

\author{
Edward A Kyser
}

\section{Savannah River Technology Center \\ Actinide Technology Section}

February 2003

\section{Summary:}

The current anion resin in use in HB-Line Phase II, Reillex ${ }^{\mathrm{TM}}$ HPQ, was tested in the laboratory under expected plant conditions for $\mathrm{Np}$ processing and was found to load between 50 and $70 \mathrm{~g} \mathrm{~Np}$ per liter of resin. Losses varied from 0.2 to 15 percent depending on a number of parameters. Hydrazine in the feed at 0.02 to $0.05 \mathrm{M}$ appeared to keep the $\mathrm{Np}$ from oxidizing and increasing the losses within four to seven days after the FS addition. Losses of up to three percent were observed five days after FS addition when hydrazine was not used in the feed, compared with 0.3 percent when the feed was loaded immediately after FS addition. Based on these test results the following processing conditions are recommended:

- Feed conditions: $8 \mathrm{M} \mathrm{HNO}_{3}, 0.02 \mathrm{M}$ hydrazine, $0.05 \mathrm{M}$ excess FS, less than 5 days storage of solution after FS addition.

- Wash conditions: 100 liters of $8 \mathrm{M} \mathrm{HNO}_{3}$, no FS, no hydrazine.

- Elution conditions: $0.17 \mathrm{M} \mathrm{HNO}_{3}, 0.05 \mathrm{M}$ hydrazine, no FS

- Precipitation feed conditions: $0.03 \mathrm{M}$ excess ascorbic acid, no additional hydrazine, no FS, precipitation within three days. 


\section{Background:}

The new HB-Line facility was designed and built in the early to mid 1980's. Phase II of HB-Line was started up to stabilize $\mathrm{Pu}$ solutions in 2001. This facility was designed to receive $\mathrm{Pu}$ (or $\mathrm{Np}$ ) nitrate solutions from $\mathrm{H}-\mathrm{Canyon}$ and convert them into oxides for storage or shipment. Currently preparations are being made to convert this facility over to processing the $\mathrm{Np}$ nitrate solutions stored in H-Canyon. After receipt of the Np solution, anion exchange columns will both purify and concentrate the Np nitrate solution, after which it will be converted to an oxide via oxalate precipitation, filtration, and calcination. The existing tanks and interconnecting piping associated with anion exchange are shown in Figure 1.

Figure 1. Process Flow Diagram of Anion Exchange Process in HB-Line

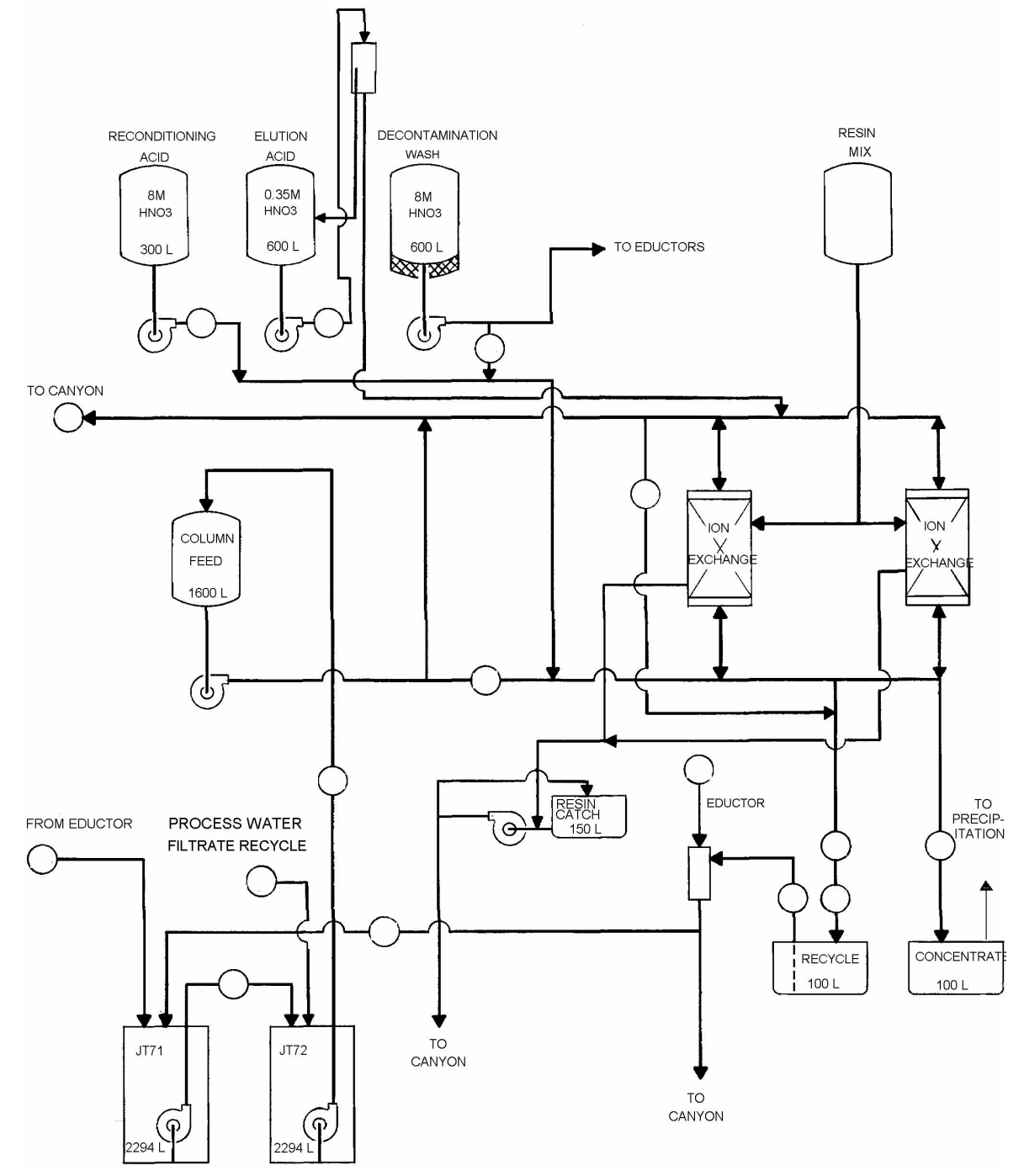

$\mathrm{Np}$ solution will be received from H-Canyon as a moderately concentrated Np nitrate solution (15-20 g $\mathrm{Np} / \mathrm{L}, 1.6-5 \mathrm{M} \mathrm{HNO}_{3}$ ). Valence and acid concentration adjustment will be performed in a feed adjustment tank (JT72) via the addition of $\mathrm{FS}, \mathrm{N}_{2} \mathrm{H}_{4}$ and $64 \% \mathrm{HNO}_{3}$. In the past, $\mathrm{Np}$ valence adjustment was performed by adding sufficient $\mathrm{N}_{2} \mathrm{H}_{4}$ and FS to make the solution $0.02 \mathrm{M} \mathrm{N}_{2} \mathrm{H}_{4}$ and $0.05 \mathrm{M} \mathrm{FS}$. $\mathrm{N}_{2} \mathrm{H}_{4}$ is added to react with $\mathrm{HNO}_{2}$ produced via radiolysis and to protect the $\mathrm{Fe}^{2+}$ and $\mathrm{Np}^{4+}$ from oxidation. The $\mathrm{FS}$ reduces all $\mathrm{Np}^{5+, 6+}$ to $\mathrm{Np}^{4+}$ and all $\mathrm{Pu}^{4+, 5+, 6+}$ to $\mathrm{Pu}^{3+}$. $\mathrm{Np}^{4+}$ is the only oxidation state of $\mathrm{Np}$ that forms the anionic nitrate complex that significantly loads onto anion resin. The high nitrate concentration and radiolysis will produce sufficient $\mathrm{HNO}_{2}$ to oxidize both the $\mathrm{Fe}^{2+}$ and $\mathrm{Pu}^{3+}$ after several days to several weeks. When Pu has been processed in the past, either a nitrite addition step or a "heat-kill" step was included to rapidly oxidize the $\mathrm{Pu}^{3+}$ to the absorbable $\mathrm{Pu}^{4+}$ valence state. In the $\mathrm{Np}$ process, $\mathrm{Np}^{4+}$ is the desired species and it is desirable to reject $\mathrm{Pu}$ to the raffinate 
stream. However $\mathrm{Pu}^{3+}$ tends to oxidize to the $\mathrm{Pu}^{4+}$ valence state in high nitrate solution which loads onto anion exchange resin even more strongly than $\mathrm{Np}^{4+}$. In the baseline process for $\mathrm{Np}$ purification, the nitrate concentration was lowered to 5.4-6.5 $\mathrm{M} \mathrm{HNO}_{3}$ in the presence of FS to weaken the tendency for the absorbable $\mathrm{Pu}\left(\mathrm{NO}_{3}\right)_{6}{ }^{2-}$ complex to form so that $\mathrm{Pu}$ could be rejected to the raffinate stream.

The anion column will be prepared for a Np run by "reconditioning" the resin bed with a quantity of $8 \mathrm{M} \mathrm{HNO}_{3}$ passed through the piping and the bed to flush dilute acid from the system. HB-Line will pump the adjusted feed from the receipt/feed adjustment tanks to a column feed tank. The feed solution will be pumped up-flow through the column, absorbing the anionic $\mathrm{Np}\left(\mathrm{NO}_{3}\right)_{6}{ }^{2-}$ complex as it passes through the resin bed. The column raffinate (which contains the cationic metal impurities and is normally waste) will be transferred directly to an $\mathrm{H}$-Canyon tank. After a full batch of $\mathrm{Np}$ feed solution has been loaded onto the column (probably using one-half to two-thirds of the resin bed's physical capacity), the bed will be washed up-flow. This step moves the remaining $\mathrm{Np}$ solution into the resin bed where the remaining $\mathrm{Np}$ will absorb and also provides improved decontamination from impurities by displacing residual impure solution from the equipment prior to elution. In the baseline flowsheet, a partitioning wash was used to wash out additional $\mathrm{Pu}^{238}$ crosscontamination. This partitioning wash used a lower $\mathrm{HNO}_{3}$ concentration (5.5-6.4 M), $\mathrm{N}_{2} \mathrm{H}_{4}$ (to scavenge the $\mathrm{HNO}_{2}$ ) and FS (to reduce the Pu). In old HB-Line, this step was typically performed when additional $\mathrm{Pu}^{238}$ removal was desired. The $\mathrm{Np}$ will then be eluted with $0.17 \mathrm{M} \mathrm{HNO}_{3}$ by gravity feed from a head tank "downflow" through the column. The elution stream passes through a sight-glass that is instrumented with fiber optics to a colorimeter to determine the point to start collecting Np into the product concentrate tank. The initial effluent from the column collected during elution is commonly referred to as the "heads cut". The high Np concentration solution collected next is referred to as the "hearts" or product cut. Any dilute acid concentration, dilute $\mathrm{Np}$ concentration solution collected near the end of the elution is referred to as the "tails" cut. At the end of a column run, the column is left in a dilute acid concentration state with little or no Np heel. The resin is considered to be in a safe condition for storage until the next run. The NaI detectors on the process equipment and streams that were used for $\mathrm{Pu}$ processing will not be used for $\mathrm{Np}$ processing. Interference from the $\mathrm{Pa}^{233}$ daughter from $\mathrm{Np}^{237}$ decay and partial separation of the $\mathrm{Pa}$ from the $\mathrm{Np}$ will make use of those detectors impractical.

Normally an anion exchange column would only be partially loaded, leaving a large amount of excess capacity. This excess capacity results in minimal losses to the raffinate stream. The capacity of the resin must be known under normal process conditions to determine the batch size. If loading is continued, the concentration of $\mathrm{Np}$ in the raffinate stream will gradually rise until visual "break-through" occurs. After visual breakthrough, the resin continues to load $\mathrm{Np}$, but an ever-increasing fraction of the $\mathrm{Np}$ in the feed solution is not absorbed. Ultimately the Np concentration in the raffinate will reach the concentration in the feed and the resin bed will absorb no additional Np. Higher loading produces higher product concentration in the "hearts" cut. Under normal conditions it is desirable to produce a raffinate stream that has only discardable amounts Np or $\mathrm{Pu}$. This goal requires a reasonable knowledge of the capacity of the resin under processing conditions.

The anion exchange resin proposed for use in HB-Line is Reillex ${ }^{\mathrm{TM}}$ HPQ. Fred Marsh of Los Alamos National Lab (LANL) and Reilly Industries jointly developed this resin based on another polypyridine-based resin, Permutitt SK, which was used in Pu and Np processes in the late 1950's (Ref 1,2,3). Better resistance to radiolytic and chemical damage is attributed to these resins due to the presence of the pyridine ring " $\mathrm{N}$ " functional group. Marsh also found this resin to be attractive due to its relatively high loading for $\mathrm{Pu}$ and its excellent elution behavior (2). In 2000 Crooks (4) and Kyser (5) studied the loading of the current version of Reillex ${ }^{\mathrm{TM}}$ HPQ for use in the Pu columns in HB-Line. Much of the equipment and some of the procedures used in the current study are very similar to those used in the earlier work.

There are no literature studies on the loading of Reillex ${ }^{\mathrm{TM}}$ HPQ with Np. There has been very limited process development work with $\mathrm{Np}$ over the last 20 years and one objective of this work was to gain general experience with the process chemistry of $\mathrm{Np}$. The major objective however was to identify the documented safety analysis (DSA) related parameters of the process flowsheet and to propose process limits. Along the way, a number of other process parameters were also studied. One of these (as was already mentioned) was to measure the resin capacity for Np under HB-Line process conditions. As this work developed, the only process parameter that was identified as significant to the DSA was the concentration of $\mathrm{N}_{2} \mathrm{H}_{4} / \mathrm{HN}_{3}$ in the various process streams. As a result, this work focused principally on determining the levels of $\mathrm{N}_{2} \mathrm{H}_{4}$ that were needed in anion exchange and precipitation processes to minimize $\mathrm{Np}$ losses to waste. 
WSRC-TR-2003-00111, Rev 0

Table I. Comparison of SRTC Conditions to HB-Line Standard Flowsheet (Ref 6,7)

\begin{tabular}{|c|c|c|c|c|c|c|c|}
\hline & $\begin{array}{l}\text { Feed } \\
\text { High }\end{array}$ & Low & $\begin{array}{l}\text { Recon-- } \\
\text { ditioning }\end{array}$ & $\begin{array}{l}\text { Decon- } \\
\text { Wash }\end{array}$ & Elution & & \\
\hline Flow, 1/batch & 286 & 1000 & 45 & 100 & 90 & & \\
\hline Np (g/batch) & 2000 & 2000 & & 1 & & & \\
\hline $\mathrm{Np}(\mathrm{g} / \mathrm{l})$ & 7 & 2 & & 0.01 & & & \\
\hline HNO3 (M) & 8 & 8 & 8 & 8 & 0.17 & \multicolumn{2}{|l|}{ Assumptions } \\
\hline HB-Line & up & up & up & up & down & Col ID 14.75 in Column area $=$ & $1102 \mathrm{~cm}^{2}$ \\
\hline Flow $(1 / \mathrm{min})$ & 2.3 & 8 & 5 & 2.2 & 1.6 & \multicolumn{2}{|l|}{ Resin Bed Height 15 in } \\
\hline $\mathrm{v}\left(\mathrm{ml} / \mathrm{min} / \mathrm{cm}^{2}\right)$ & 2.1 & 7.3 & 4.5 & 2.0 & 1.5 & \multicolumn{2}{|l|}{ Resin Bed Volume $45 \mathrm{~L}$} \\
\hline Volume (1) & 286 & 1000 & 45 & 100 & 90 & \multicolumn{2}{|l|}{ Volumes from Flowsheet } \\
\hline Time (min) & 125 & 125 & 9 & 45 & 56 & & \\
\hline BV & 6 & 22 & 1.0 & 2.2 & 2.0 & \multicolumn{2}{|c|}{ BV=Bed Volumes (Total volume of resin bed) } \\
\hline $\mathrm{mgs} \mathrm{Np} / \mathrm{min} / \mathrm{cm}^{2}$ & 15 & 15 & & & & \multicolumn{2}{|l|}{ Assume $2 \mathrm{~g} \mathrm{~Np} / 1$ \& $7 \mathrm{~g} \mathrm{~Np} / 1$} \\
\hline SRTC Np & down & down & down & down & down & Column area $=$ & $2.835 \mathrm{~cm}^{2}$ \\
\hline Flow (ml/min) & 5 & 5 & 20 & 12 & 2 & \multicolumn{2}{|l|}{ Resin Bed Volume measured as $110 \mathrm{cc}$} \\
\hline $\mathrm{v}\left(\mathrm{ml} / \mathrm{min} / \mathrm{cm}^{2}\right)$ & 1.8 & 1.8 & 7.1 & 4.2 & 0.7 & \multicolumn{2}{|l|}{ Resin Bed Height 15.5 in } \\
\hline Volume (ml) & 500 & 1000 & 200 & 250 & 250 & \multicolumn{2}{|l|}{409} \\
\hline Time (min) & 100 & 200 & 10 & 21 & 125 & \multicolumn{2}{|l|}{ rea ratio } \\
\hline BV & 5 & 9.3 & 1.9 & 2.3 & 2.3 & & \\
\hline $\mathrm{mgs} \mathrm{Np} / \mathrm{min} / \mathrm{cm}^{2}$ & 18 & 9 & & & & \multicolumn{2}{|l|}{$10 \& 5 \mathrm{~g} \mathrm{~Np} / 1$ in Feed } \\
\hline SRTC Np & down & down & down & down & down & Column area $=$ & $2.835 \mathrm{~cm}^{2}$ \\
\hline Flow (ml/min) & 5 & 5 & 20 & 5 & 2 & \multicolumn{2}{|l|}{ Resin Bed Volume measured as $35.5 \mathrm{cc}$} \\
\hline $\mathrm{v}\left(\mathrm{ml} / \mathrm{min} / \mathrm{cm}^{2}\right)$ & 1.8 & 1.8 & 7.1 & 1.8 & 0.7 & \multicolumn{2}{|l|}{ Resin Bed Height 5 in } \\
\hline Volume (ml) & 200 & 400 & 100 & 100 & 160 & \multicolumn{2}{|l|}{ resin ratio } \\
\hline Time (min) & 40 & 80 & 5 & 20 & 80 & \multicolumn{2}{|l|}{ area ratio } \\
\hline BV & 6 & 11 & 2.8 & 2.8 & 4.4 & & \\
\hline $\mathrm{mgs} \mathrm{Np} / \mathrm{min} / \mathrm{cm}^{2}$ & 18 & 9 & & & & \multicolumn{2}{|l|}{$10 \& 5 \mathrm{~g} \mathrm{~Np} / 1$ in Feed } \\
\hline
\end{tabular}

\section{Experimental Column Operation}

Process Flowrate Scaling: Plant scale anion exchange equipment is typically 100 to 1000 times larger than laboratory equipment. Normally the process is scaled based on the linear velocity $\left(\mathrm{Q} / \mathrm{A}, \mathrm{mL} / \mathrm{min} / \mathrm{cm}^{2} \equiv\right.$ $\mathrm{cm} / \mathrm{min}$ ) through the resin bed (which is related to residence time in the bed) and the loading profile of the resin. If a laboratory column contains resin at the same depth as the plant equipment, then the scaling problem is primarily reduced to one of linear velocity. However, higher Np concentrations in the feed solution will produce a higher $\mathrm{Np}$ resin loading. Lower flowrates would also tend to increase the effective loading by increasing the time for mass transfer. For these experiments, a resin volume of $36 \mathrm{~cm}^{3}$ of settled resin was used in a 19 mm ID glass column, resulting in a cross sectional area of $2.835 \mathrm{~cm}^{2}$. A single run was performed with a 15 ", $(38 \mathrm{~cm})$ resin bed $\left(19 \mathrm{~mm}\right.$ ID column, $108 \mathrm{~cm}^{3}$ of settled resin). The baseline flowsheet $(6,7)$ was based on feed concentration of $2 \mathrm{~g} \mathrm{~Np} / \mathrm{L}$ that corresponds to $14.5 \mathrm{mg} / \mathrm{min} / \mathrm{cm}^{2}$. Depending how solutions are recycled in the facility, feed concentrations of anywhere from 2 to $10 \mathrm{~g} \mathrm{~Np} / \mathrm{L}$ are expected to be processed. Hill (9) recommended a loading rate of $5-10 \mathrm{mg} / \mathrm{min} / \mathrm{cm}^{2}$, which is somewhat lower than the baseline rate. Table I shows a comparison between the baseline design flowsheet and current SRTC test conditions.

Resin Pretreatment: Unlike the earlier Pu work, no resin pretreatment was performed. All resin that was tested came from the same 1998 manufacturer's lot (\#80302MA) that was purchased by SRTC for Pu flowsheet work. All resin was initially converted from the chloride form (as-shipped) to the nitrate form by washing with $1 \mathrm{M} \mathrm{NaNO}_{3}$ (10 BV in a column was the preferred method, but other methods are acceptable).

Column Loading: A sufficient quantity of resin was converted into the nitrate form prior to loading the column. The resin is generally loaded either by pouring dry resin beads into the column and then wetted with water or dilute $\mathrm{HNO}_{3}$ or by slurrying the resin into the column with water. The resin bed is settled by running water/dilute $\mathrm{HNO}_{3}$ downflow through the resin bed to fill the excess void spaces until all apparent gaps are filled. The final resin bed volume is adjusted by adding a small amount of resin or removing excess resin with a slurry pipette. Once the resin is loaded and settled into the column, every effort is made to not allow the liquid head above the resin to drain below the top of the resin bed. Air bubbles trapped within the moist bed are often very difficult to remove and will cause channeling of the flow through the bed. On several occasions a large gap formed within the resin bed. This gap was removed by tilting the column sideways or even removing the entire resin bed in order to restore a continuous resin bed. 
Feedstock Preparation and Valence Adjustment: Np solution is prepared by adjusting the $\left[\mathrm{HNO}_{3}\right]$ to 5.5 to $8.5 \mathrm{M}$ (depending on the objectives of the test) and performing a valence adjustment with $\mathrm{N}_{2} \mathrm{H}_{4}$ and/or FS. Normally $\mathrm{N}_{2} \mathrm{H}_{4}$, if used, was added first (in order to scavenge any residual $\mathrm{HNO}_{2}$ ). Then sufficient FS was added to make the solution 0.03 to $0.05 \mathrm{M}$ excess FS over that required to reduce all the $\mathrm{Np}$ from $\mathrm{Np}^{5+}$ to $\mathrm{Np}^{4+}$. The FS also reduces all $\mathrm{Pu}^{4+, 5+, 6+}$ to $\mathrm{Pu}^{3+}$. The high nitrate concentration gradually produces sufficient $\mathrm{HNO}_{2}$ to oxidize both the $\mathrm{Fe}^{2+}$ and $\mathrm{Pu}^{3+}$. In $8 \mathrm{M} \mathrm{HNO}_{3}$ at $50^{\circ} \mathrm{C}$, the half-life for $\mathrm{Fe}^{2+}$ is on the order of 10 minutes compared with $1 \mathrm{hr}$ at $35^{\circ} \mathrm{C}$ and $10 \mathrm{hr}$ at $25^{\circ} \mathrm{C}$ (8). That reference is for Pu solutions and due to the reduced alpha activity of the $\mathrm{Np}$ feed solution, $\mathrm{Fe}^{2+}$ is expected to persist for longer periods of time. $\mathrm{FS}$ degrades to $\mathrm{Fe}^{3+}$ and $\mathrm{SO}_{4}{ }^{2-}$. $\mathrm{Fe}^{3+}$ reduces the effectiveness of $\mathrm{Fe}^{2+}$ in the reduction and stability of $\mathrm{Np}$ as $\mathrm{Np}^{4+}$. Repeated additions of FS will result in increased levels of $\left[\mathrm{SO}_{4}{ }^{2-}\right]$ in the feed and will both increase the raffinate losses due to $\mathrm{SO}_{4}{ }^{2-}$ complexation with $\mathrm{Np}^{4+}$ and reduce the resin capacity for $\mathrm{Np}$. The effect of $\mathrm{SO}_{4}{ }^{2-}$ on anion resin capacity was studied by Burney (10). He observed a $30 \%$ reduction in capacity for $0.1 \mathrm{M} \mathrm{SO}_{4}{ }^{2-}$ and a $70 \%$ reduction in capacity for $0.5 \mathrm{M} \mathrm{SO}_{4}{ }^{2-}$ in $8 \mathrm{M} \mathrm{HNO}_{3}$. Due to tank heels in the feed tanks, some buildup of $\left[\mathrm{SO}_{4}{ }^{2-}\right]$ is inevitable and may have an effect on capacity. In this study the anion exchange feed was normally started promptly after the FS addition except when the effect of hold time was to be studied.

Lab Equipment: One of the columns used in this work is shown in Figure 2. This picture shows the $\mathrm{Cr} 238$ upload column with a partial load of $\mathrm{Np}$ on the resin. The $\mathrm{Np}$ loaded resin is characterized by the gray color on the lower $40 \%$ of the bed. This column utilized \#7 Teflon ${ }^{\mathrm{TM}}$ bushings for connecting $1 / 4 \mathrm{inch}$ polypropylene tubing to the column. The column consists of a $19 \mathrm{~mm}$ ID glass body to retain the resin bed and a headpiece. The headpiece attached to the column body with a Rodaviss ${ }^{\mathrm{TM}}$ joint to allow the column to retain a larger pressure head than that allowed by a ground glass joint. As a safety precaution, the head also had a Ace glass pressure relief valve and a pressure gauge to monitor the pressure in case the frit at the bottom of the column plugged. An additional arm with a stopcock and funnel allowed the column to be vented. The primary column used in the loading studies utilized a short ( 5 in $)$ resin bed and was operated down-flow only. A second column was similar in design, but provided for a full height $(\sim 15 \mathrm{in})$ resin bed. The tall column is the version shown in Figure 3. With the use of 100 mesh screen held into place with an o-ring, this column was operated load-wash up-flow and elution down-flow. A sketch of the experimental setup for the loading tests (which were run down-flow) is shown as Figure 3.

A standard FMI piston pump was used to pump feed, wash, or elution acid through the column. A $1 / 2$ inch Swaglock ${ }^{\mathrm{TM}}$ cross and $1 / 2$ inch optic lens was used to fabricate a flowcell with a $2.54 \mathrm{~cm}$ pathlength. A pair of fiber optic lines previously installed through the ceiling of the glovebox allowed a light signal to be brought into the glovebox, passed through the flowcell and carried out to a Zeiss spectrometer controlled by an NTbased computer. A detailed parts list for the complete spectrophotometer system used is given in Table II. The multiplexer used in past work proved unsuitable for this work as it used UV grade fibers (high $\mathrm{OH}$ ) which absorbed all the light in the $950 \mathrm{~nm}$ wavelength range. $\mathrm{Np}^{4+}$ and $\mathrm{Np}^{5+}$ absorption peaks at $960 \mathrm{~nm}$ and $980 \mathrm{~nm}$ were not useable if any high $\mathrm{OH}$ fibers were used. Therefore, the multiplexer was bypassed and reference and

Figure 2. Column used in Experiments

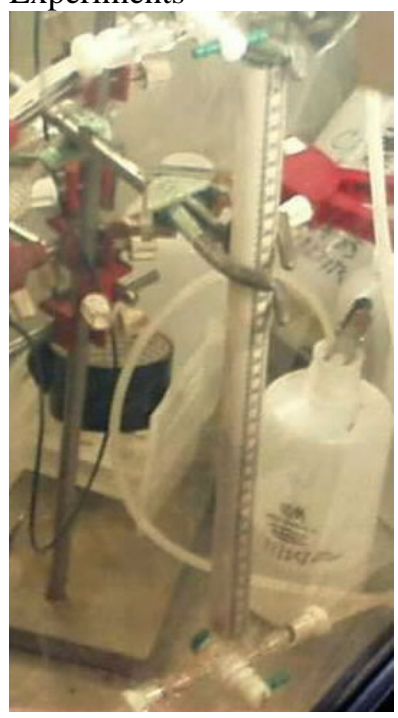

Figure 3. Experimental Setup

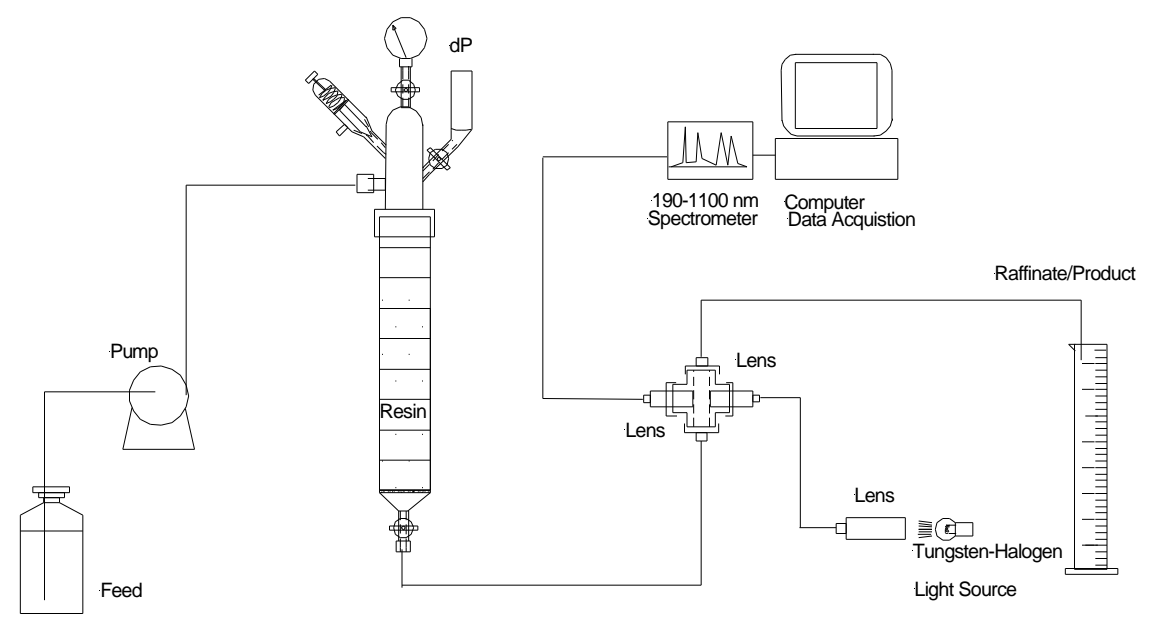


Table II. Spectrophotometer System Parts List

- $\quad$ Spectrometer: Diode array spectrometer based on the Zeiss MCS module (190-1024 nm range, approximately 0.8 nm/pixel). Interfaced to computer through Hamamatsu C4070 driver/amplifier board. Power supply: Condor D.C. Power supplies model MTLL-5W-A.

- $\quad$ Fiber optic cable: Ceramoptec or Polymicro, 400 micron low-OH core with SMA fittings each end

- $\quad$ Computer: Texas Micro industrial PC, IPC-6806P.233MHz, Windows NT

- Data acquisition card: National Instruments AT-AI-16XE-10 Multiple I/O Board (16-bit resolution, 16 analog and 8 digital inputs).

- Flowcell: Swaglock 1/2 “Union Cross (SS-810-4) for body, Swaglock 1/4" to 1/2 " Reducer (SS-400-R-2) 2 each to attach 1/4" poly tubing, Fiber optic Lens: Equitech CL-UV-K. Stainless steel body, 1/2" diameter. Quartz lens. Kalrez o-ring seal. Stainless SMA connector, 2 required

- $\quad$ Light Source: Ocean Optics Tungsten Halogen LampHousing, LS-1

- Variable Attentuator Oz Optics Part \# BB-200-55-300 600-SP to adjust light levels

- Cuvette Blocks: SRTC fabricated plexiglass cuvette holders each with 2 lenses similar to flowcell, 1 unit for light reference and 1 for glovebox standards

measurement spectra were taken on the same pair of fibers.

Np Loading: Sufficient Np feedstock was prepared for one or more break-through column runs. A sample was taken and analyzed for total acid/free acid, total alpha by alpha PHA and gamma scan. At the beginning of the column run, several column volumes of 6-8 $\mathrm{M} \mathrm{HNO}_{3}$ were fed to the column to displace the dilute acid the resin was stored in from the previous run. At this point in time the spectrophotometer was checked for proper operation and a new "zero" spectrum was stored (background with no Np in the flow cell). The Np feed was then pumped downflow through the column at approximately the desired flowrate, with the raffinate passing through the flow cell and being collected and measured in one of several graduated cylinders. The amount of $\mathrm{Np}$ in the raffinate was monitored by both visual inspection and by periodic spectra . "Grab" samples of the raffinate were also taken on a periodic basis during the course of the loading step and analyzed for $\mathrm{Np}$ content by alpha and gamma counting. The spectra taken were stored along with the time and volume of raffinate collected. The feed flowrate was periodically checked with a $10 \mathrm{~mL}$ graduated cylinder and a stopwatch. The flowrates were somewhat variable (sometimes $\pm 50 \%$ of the targeted value), but the average flowrate could generally be regulated within $15 \%$ of the desired value.

The Np loaded onto the resin was also visually monitored. Visual monitoring of the Np loaded onto the resin was more difficult than the previous observations with Pu. The appearance of Np proved difficult to recognize until after break-through had occurred. Flow abnormalities within the resin bed sometimes caused "tailing" of the loaded $\mathrm{Np}$ (e.g. Np loaded non-uniformly on the resin where the Np interface is further down the resin bed on one side of the column than the other). This behavior was not observable for Np like it had been during similar Pu runs due to the subtle color change, but it probably occurred. Tailing could cause higher than expected losses to the raffinate or wash. As the Np interface (observed as a gray boundary) approached the bottom of the resin bed the levels of $\mathrm{Np}$ in the raffinate rose gradually (to $\sim 0.1 \mathrm{~g} \mathrm{~Np} / \mathrm{L}$ ) and the frequency of spectra measurements was increased. Pu "break-through" was readily determined by visual observation of the raffinate in the 0.5 to $1 \mathrm{~g} \mathrm{Pu} / \mathrm{L}$, but the corresponding break-though of $\mathrm{Np}$ was less readily detected and was easily missed when column run was performed without aid of the spectrometer. With the spectrometer and 2.54 $\mathrm{cm}$ flowcell, "visual-breakthrough" was declared in the 0.2 to $0.5 \mathrm{~g} \mathrm{~Np} / \mathrm{L}$ concentration range. For a period of time before and after visual break-through, the Np concentration in the raffinate rapidly rises from $<0.1$ to $\sim 2 \mathrm{~g}$ $\mathrm{Np} / \mathrm{L}$. As loading continues, the concentration continues to rise, but more slowly as it asymptotically approaches that of the feed concentration. During this time, a significant fraction of the $\mathrm{Np}$ in the feed solution continues to load onto the resin as Np diffuses deeper into the resin beads and the resin becomes saturated with $\mathrm{Np}$. The raffinate was commonly collected in two cuts. The first was collected up to the point that visual break-through was detected and the second was collected from that point past the end of the loading phase. The decontamination wash was usually collected separately. This method of collection allowed the early raffinate to be discarded, while recycling the raffinate after break-through. Only a few runs were made for saturation loading or break-through studies. A number of runs were made to study the effect of $\left[\mathrm{N}_{2} \mathrm{H}_{4}\right]$ and time on the losses to the raffinate stream. These runs were not fundamentally different than the break-through runs, but the results relied more on results from analytical analyses than on results from online spectrometer results.

Reductive Loading/Washing: In the beginning of this study, there was interest in attempting to reject $\mathrm{Pu}^{238}$ contamination. The $\left[\mathrm{HNO}_{3}\right]$ was reduced from $8 \mathrm{M}$ to $5.5-6.5 \mathrm{M}$ in an attempt to increase the stability of

$\mathrm{Pu}^{3+}$ in the feed solution. Adjustments to the $\mathrm{HNO}_{3}, \mathrm{FS}$ and $\mathrm{N}_{2} \mathrm{H}_{4}$ concentrations in both the feed and wash solutions were made in an attempt to reject $\mathrm{Pu}^{238}$ as $\mathrm{Pu}^{3+}$ to the raffinate stream. 
Figure 4. $\mathrm{Np}^{5+}$ Spectra in Low $\mathrm{HNO}_{3}$

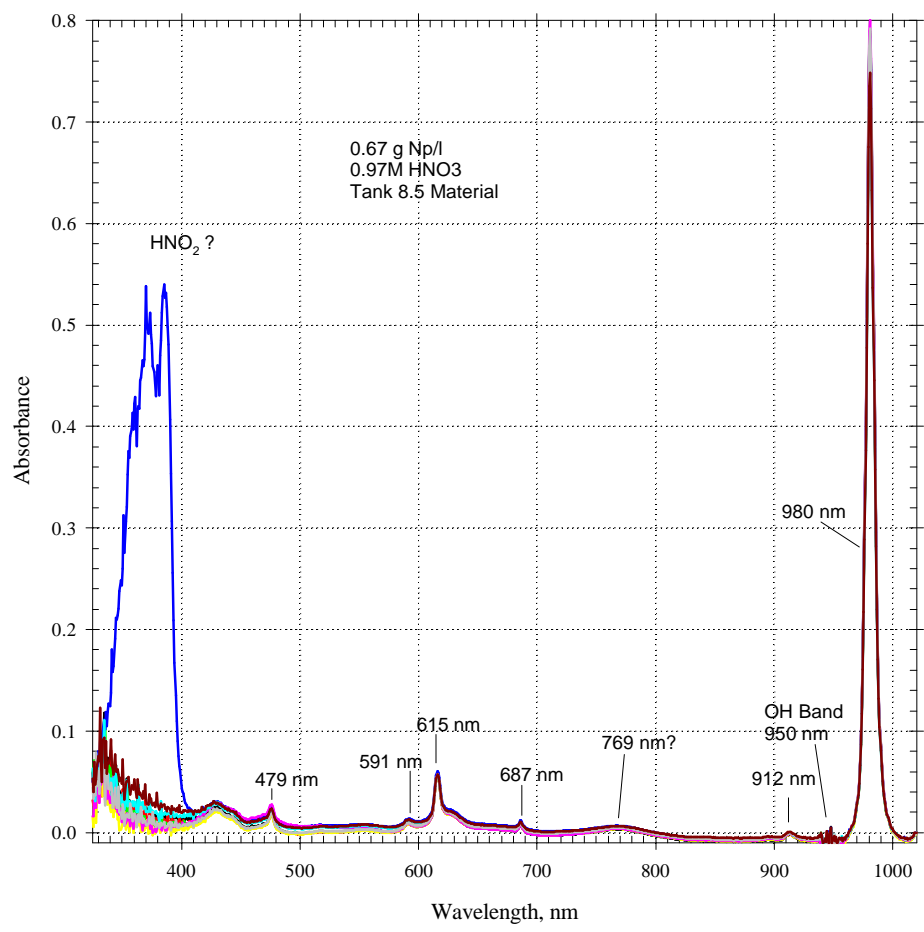

Figure 5. $\mathrm{Np}^{4+}$ Spectra in Low and High $\mathrm{HNO}_{3}$ Compared with $\mathrm{Np}^{5+}$ Spectra

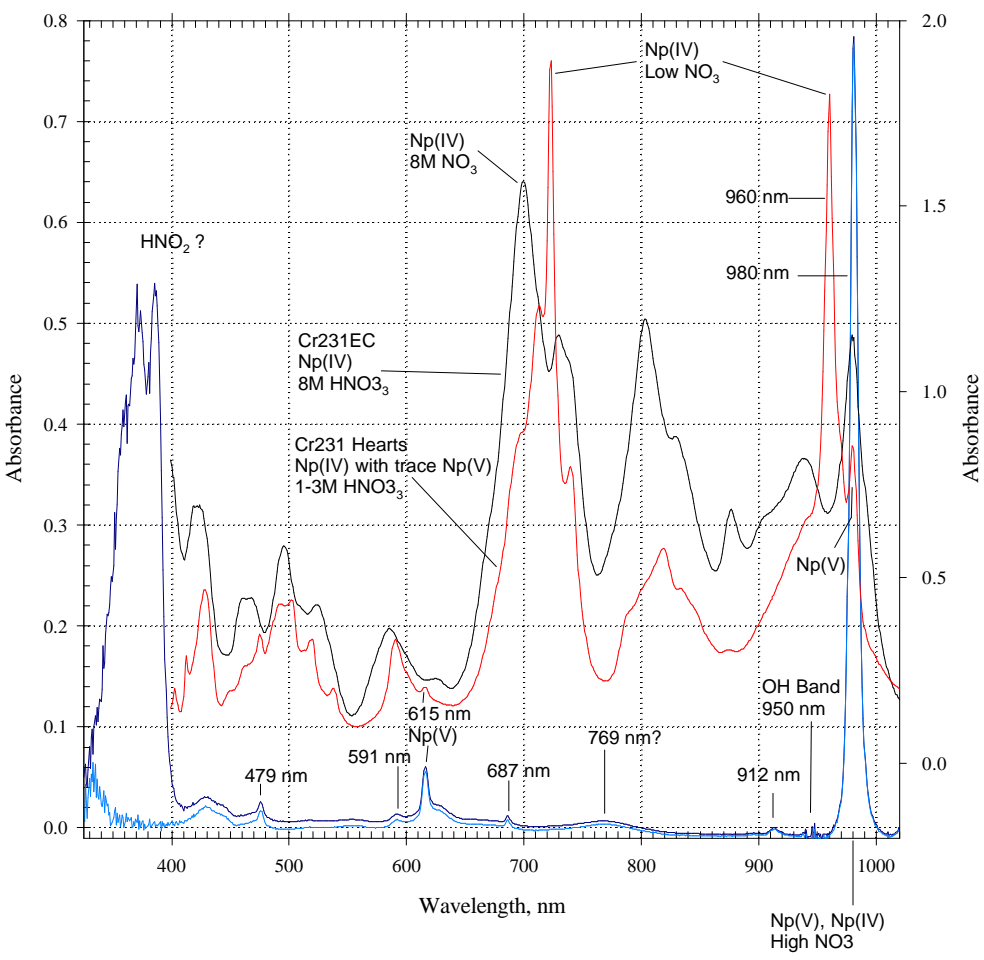

Np Washing and Elution: When the concentration in the raffinate was approximately $90 \%$ of that in the feed (or when the prepared feedstock was exhausted), the loading was stopped. Allowances then had to be made to displace the residual $\mathrm{Np}$ feed solution from the resin bed and feed line. There was unloaded $\mathrm{Np}$ in the system due to void space in the column $(\sim 50$ volume percent or 18 $\mathrm{mL}$ ), the head-liquid volume above the resin $(10$ to $40 \mathrm{~mL})$ and finally the liquid volume still in the feed-line $(<10 \mathrm{~mL})$. Normally this uncertainty was eliminated by pumping the feed line dry and allowing the head liquid to drain (without letting the level drop below the top of the resin) to a minimal volume above the resin bed ( 0 to 5 $\mathrm{mL}$ ). A short decontamination wash of the resin column with $100 \mathrm{~mL}$ of 8 $\mathrm{M} \mathrm{HNO}_{3}$ was performed to remove most of the FS and displace the residual $\mathrm{Np}$ feed solution. This wash was included with the second raffinate cut for material balance purposes and future recovery of the $\mathrm{Np}$. The column was then completely eluted with 200 to $400 \mathrm{~mL}$ of $0.17 \mathrm{M} \mathrm{HNO}_{3}$ at 2 $\mathrm{mL} / \mathrm{min}$ downflow. After the visible $\mathrm{Np}$ had been removed from the resin, the run could be safely interrupted at this point and the remainder of the elution could be continued the next day.

Analytical: Samples were taken of feed solutions and composite raffinate and product solutions, as well as grab samples of the raffinate stream. These samples were routinely analyzed by alpha PHA and gamma scan analyses to determine the activity from $\mathrm{Pu}^{238}, \mathrm{Pu}^{239}, \mathrm{~Np}^{237}$ and $\mathrm{Pa}^{233}$. $\mathrm{Np}^{237}$ (2.2e6 yr half life) and $\mathrm{Pa}^{233}$ (27.4 day half life) would approach secular equilibrium after three to six months. The anion exchange process largely separates $\mathrm{Np}$ from $\mathrm{Pa}$ and the raffinate and wash samples can have a $\mathrm{Pa}^{233} / \mathrm{Np}^{237}$ activity ratio of greater than 10. Under these conditions, gamma counting was not able to provide good $\mathrm{Np}^{237}$ results due to interference from the $\mathrm{Pa}^{233}$. When $\mathrm{Pu}^{238}$ activity is greater than 10 times 
the $\mathrm{Np}^{237}$ activity the precision of the $\mathrm{Np}^{237}$ counting is also reduced. Under circumstances of both high $\mathrm{Pa}^{233}$ and $\mathrm{Pu}^{238}$ activity relative to $\mathrm{Np}^{237}$, no good method of determining the $\mathrm{Np}^{237}$ concentrations was available.

In anion feed solutions with high nitrate concentrations, a method was needed to study the oxidation of $\mathrm{Np}^{4+}$ to $\mathrm{Np}^{5+}$. SRTC-ADS adapted an existing analytical separation method to perform a $\mathrm{Np}^{4+}-\mathrm{Np}^{5+}$ separation and to then use gamma counting to determine the percent $\mathrm{Np}^{5+}$ in the sample. This experimental technique used Eichrom TEVA resin cartridges (which contain Aliquat 336, a quaternary amine loaded onto a polymer backbone). This technique appears to provide results with a sensitivity of at least $0.2 \%$ for determining the percent $\mathrm{Np}^{5+}+\mathrm{Np}^{6+}$ depending on the level of interference from $\mathrm{Pa}^{233}$.

Calibration of Spectrophotometer: Np spectra have a fairly high acid dependence. Efforts to calibrate the spectrometer for $\mathrm{Np}^{4+}$ and/or $\mathrm{Np}^{5+}$ proved to be too time consuming for the scope of this program. Instead the spectrometer was used to provide qualitative results on presence of $\mathrm{Np}^{5+}$. Semi-quantitative results on the oxidation of $\mathrm{Np}^{4+}$ to $\mathrm{Np}^{5+}$ in low acid were obtained by observing the height of the $980 \mathrm{~nm} \mathrm{~N} \mathrm{~N}^{5+}$ peak. Spectra of pure $\mathrm{Np}^{5+}$ from diluted samples of tank 8.5 material are shown in Figure 4. A number of minor peaks are shown as well as the dominant peak at $980 \mathrm{~nm}$. Absorbance caused by $\mathrm{HNO}_{2}$ (from added $\mathrm{NaNO}_{2}$ ) was observed in one sample. In $8 \mathrm{M} \mathrm{HNO}_{3}$ the absorptivity of $\mathrm{Np}^{5+}$ at $980 \mathrm{~nm}$ appeared to reduced by $90 \%$ and the disproportion clearly occurred within minutes to hours. Literature references for $\mathrm{Np}$ spectroscopy in $\mathrm{HNO}_{3}$ are limited. Johnson and Shepard (11) measured spectra of $\mathrm{Np}^{4+, 5+, 6+}$ in 1 to $10 \mathrm{M} \mathrm{HNO}_{3}$. They found a strong nitrate dependence on the spectra between 5 and $10 \mathrm{M} \mathrm{HNO}_{3}$. They also report disproportionation of $\mathrm{Np}^{5+}$ above $3 \mathrm{M} \mathrm{HNO}_{3}$. The $\mathrm{Np}^{5+}$ spectra that they published clearly show $\mathrm{Np}^{4+}$ absorption peaks, but interestingly don't show the $\mathrm{Np}^{6+}$ peaks. They also reported a strong acid dependence on this reaction. Friedman and Toth (12) report Np spectra in up to $4 \mathrm{M} \mathrm{HNO}_{3}$. They report difficulty in obtaining pure $\mathrm{Np}\left(\mathrm{IV}\right.$ ) in low $\mathrm{HNO}_{3}$ due to oxidation to $\mathrm{Np}(\mathrm{V})$. They also observed no indication of $\mathrm{Np}(\mathrm{IV})$ hydrolysis at $0.1 \mathrm{M} \mathrm{HNO}_{3}$ or above. Figure 5 shows $\mathrm{Np}^{4+}$ spectra in both low and high $\mathrm{HNO}_{3}$ compared with the reference $\mathrm{Np}^{5+}$ spectra. Note that the major $\mathrm{Np}^{4+}$ peak at $960 \mathrm{~nm}$ at low acid is shifted to $980 \mathrm{~nm}$ in $8 \mathrm{M} \mathrm{HNO}_{3}$. This shift prevents the use of the $980 \mathrm{~nm}$ peak in determining the success of valence adjustment and oxidation in anion feed solutions. Also note the appearance of characteristic $\mathrm{Np}^{5+}$ peaks at 615 and $980 \mathrm{~nm}$ in low $\mathrm{HNO}_{3}$. Attempts to prepare pure $\mathrm{Np}^{5+}$ spectra for comparison in $8 \mathrm{M} \mathrm{HNO}_{3}$ failed due to the $\mathrm{Np}^{5+}$ disproportionation to $\mathrm{Np}^{4+}$ and $\mathrm{Np}^{6+}$. 
WSRC-TR-2003-00111, Rev 0

Table III. Example of Material Balance for a Column Run

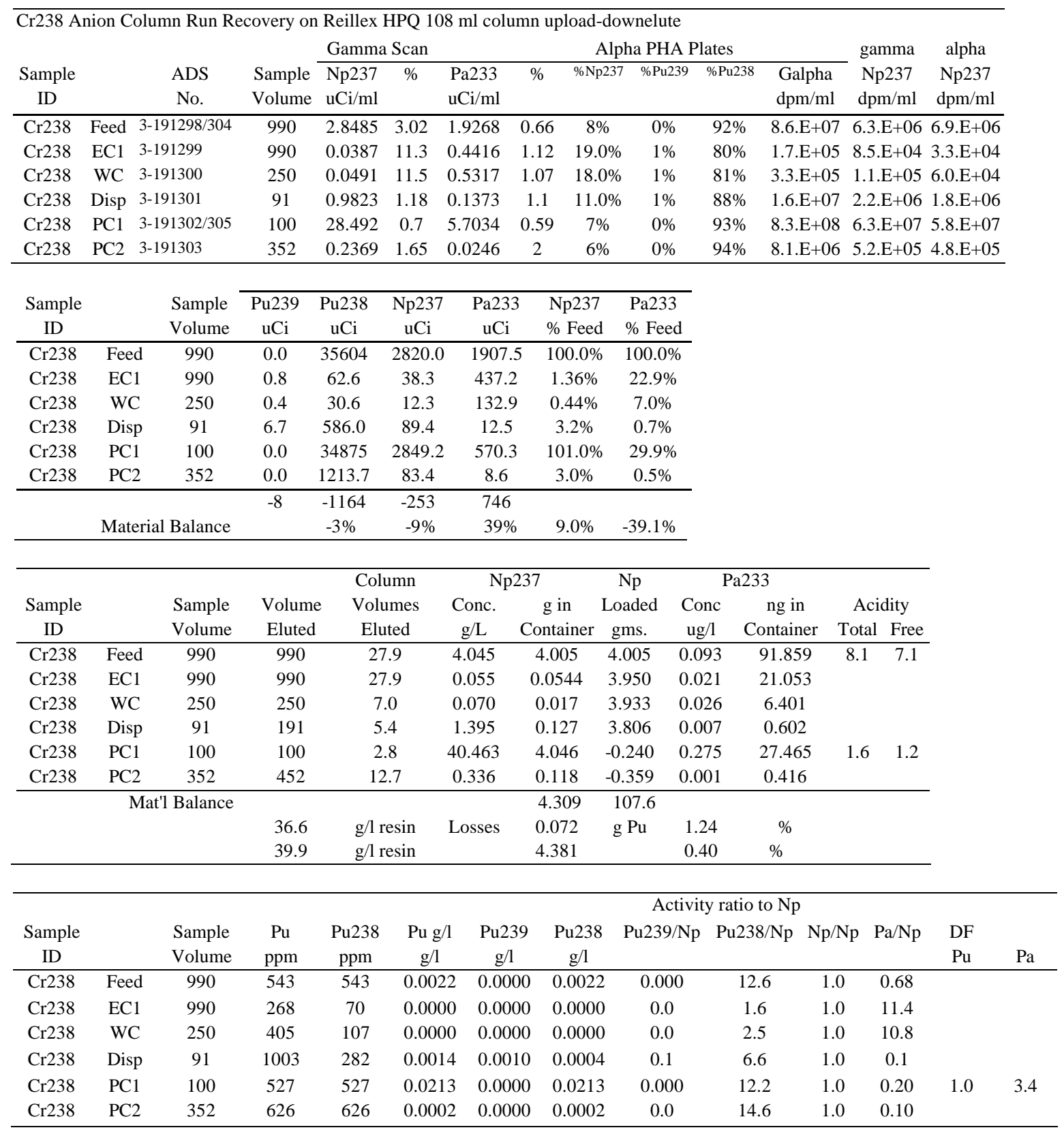


WSRC-TR-2003-00111, Rev 0

Table IV. Summary of Loading and Loss Results for Np

\begin{tabular}{|c|c|c|c|c|c|c|c|c|c|}
\hline \multirow[t]{2}{*}{ Run ID } & \multirow{2}{*}{$\begin{array}{c}\left.\mathrm{HNO}_{3}\right]^{1} \\
\text { Feed } \\
\text { M }\end{array}$} & \multirow{2}{*}{$\begin{array}{c}{\left[\mathrm{N}_{2} \mathrm{H}_{4}\right]^{2}} \\
\mathrm{M}\end{array}$} & \multirow{2}{*}{$\begin{array}{c}\mathrm{Np} \\
\text { Loading Rate } \\
\mathrm{mg} / \mathrm{min} / \mathrm{cm}^{2}\end{array}$} & \multicolumn{3}{|c|}{ Resin Loading } & \multirow{2}{*}{$\begin{array}{c}\text { Time Between } \\
\text { FS and Loading } \\
\text { days }\end{array}$} & \multicolumn{2}{|c|}{ Np Losses } \\
\hline & & & & $\begin{array}{r}\text { Breakthru } \\
\text { gn }\end{array}$ & $\begin{array}{l}\text { Saturation } \\
\mathrm{Np} / \text { liter res }\end{array}$ & Loaded & & \multicolumn{2}{|l|}{$\%$ of Feed } \\
\hline $\mathrm{Cr} 221$ & 6.4 & 0.05 & 17.0 & $\sim 40$ & 74 & & 0.1 & na & \\
\hline $\mathrm{Cr} 222$ & 6.4 & 0.05 & 17.0 & 44 & 76 & & 5 & 0.4 & 3 \\
\hline $\mathrm{Cr} 223$ & 6.4 & 0.1 & 2.4 & & & 16 & 0.1 & 0.6 & \\
\hline $\mathrm{Cr} 224$ & 6.4 & 0.05 & 5.0 & & & 31 & 7 & 0.3 & \\
\hline $\mathrm{Cr} 225$ & 6.4 & 0.02 & 6.8 & & & 46 & 0.1 & 0.14 & \\
\hline $\mathrm{Cr} 226$ & 7.6 & 0.02 & 17.0 & 71 & 80 & & 0.1 & 0.2 & 3 \\
\hline $\mathrm{Cr} 227$ & 7.4 & 0.02 & 7.4 & & & 61 & 4 & 3.2 & 3 \\
\hline $\mathrm{Cr} 228$ & 6.4 & 0.036 & 2.6 & & & 9 & 0.1 & 0.12 & \\
\hline $\mathrm{Cr} 229$ & 6.6 & 0.005 & 7.0 & & & 16 & 0.1 & 0.01 & \\
\hline $\mathrm{Cr} 230$ & 5.7 & 0.008 & 12.0 & 36 & & 45 & 0.1 & 0.3 & 3 \\
\hline $\mathrm{Cr} 231$ & 8.2 & 0 & 15.0 & & & 51 & 0.1 & 0.5 & \\
\hline $\mathrm{Cr} 232$ & 8 & 0 & 12.0 & & & 38 & 0.1 & 0.12 & \\
\hline $\mathrm{Cr} 233$ & 8 & 0 & 5.3 & & & 39 & 0.1 & 15 & 3 \\
\hline $\mathrm{Cr} 235$ & 8 & 0 & 6.6 & & & 29 & 0.1 & 4.6 & \\
\hline $\mathrm{Cr} 237$ & 8 & 0 & 8.4 & & & 53 & 5 & 2.5 & 4 \\
\hline \multirow[t]{5}{*}{ Cr238 } & 8 & 0 & 8.0 & & & 40 & 5 & 1.8 & 4 \\
\hline & 1 & Values deter & ed by either cal & lation or by & analysis & & & & \\
\hline & 2 & Values deter & ed by calculatic & only & & & & & \\
\hline & 3 & Losses to raf & te up to detecta & e breakthru & $0.2 \mathrm{~g} \mathrm{~Np} / \mathrm{l})$ & & & & \\
\hline & 4 & No spectrom & available to de & rmine visua & breakthru & & & & \\
\hline
\end{tabular}

\section{Results and Discussion:}

A series of column runs was performed with the 1998 batch of Reillex ${ }^{\mathrm{TM}}$ HPQ purchased for development of the Pu flowsheet. For each experiment, composite samples of the feed, raffinate, and product solutions were analyzed (along with selected "grab" samples) and submitted for analysis. The results from those analyses and the volume of each solution were used to calculate a material balance for each experiment. The amount of $\mathrm{Np}$ absorbed onto the resin was calculated as the difference between the cumulative amount fed and the amount found in the raffinate solutions. This method was used to calculate the visual break-through loading of the resin (where applicable). The saturated loading was also calculated in this same fashion (where applicable) and was checked by measuring the total amount of Pu found in the eluate (product) solutions. A sample set of results for one of the column runs and some sample calculations for that run are shown in Table III. Additional results for the other runs are shown in Tables IV and VII.

Resin Loading and Losses: Table IV summarizes the Np loading results for the 16 column runs that used the 1998 lot of Reillex ${ }^{\mathrm{TM}} \mathrm{HPQ}$. Some of these runs were made to recover Np and did not involve loading to break-through. Feed concentrations and conditions varied somewhat and are shown in Table VII. Results include conditions for Pu rejection and for maximum Np loading. For the Pu rejection runs $\left(\mathrm{N}_{2} \mathrm{H}_{4}, \mathrm{FS}\right.$ and lower feed acidity) break-through occurred at $\sim 36-44 \mathrm{~g} \mathrm{~Np} / \mathrm{L}$ resin without any contradictory results. For the maximum Np loading runs ( 8 $\mathrm{M} \mathrm{HNO}_{3}$ ) break-through occurred at $51-71 \mathrm{~g} \mathrm{~Np} / \mathrm{L}$ resin with several exceptions that showed high losses. Because the $\mathrm{N}_{2} \mathrm{H}_{4}$ concentration and the age of the feed solution were being varied at the same time, the higher losses may have been caused by $\mathrm{Np}$ oxidation state changes rather than capacity limitations. The appearance of $650-750 \mathrm{~nm} \mathrm{~Np}^{4+}$ absorbance peaks indicated that the losses measured in the raffinate cut were due to break-through either from lack of capacity, too high of a feed rate, or channeling rather than due to incomplete reduction or oxidation. However, experimental evidence linking higher losses to the valence state was generally not available. Other factors may have contributed to these higher losses as well. Flowrates were varied and $\mathrm{SO}_{4}{ }^{2-}$ levels in the feed were different between these runs. A definitive explanation for the variation in the losses has not been identified from the data available. In similar testing that was performed for Pu loading (10), the issue of losses was not considered as critical of an issue as it has been with $\mathrm{Np}$ (due to the relatively high solubility of $\mathrm{Np}^{5+}$ in HLW supernate and the low limits for $\mathrm{Np}$ in saltstone). For this $\mathrm{Np}$ study, the effect of $\mathrm{N}_{2} \mathrm{H}_{4}$ concentration in the feed on $\mathrm{Np}$ losses over various feed hold times has prompted extra attention to losses. A complete understanding of all the parameters that lead to elevated $\mathrm{Np}$ losses to the raffinate during the course of this study has not been possible in the time allowed. 
Table V. Oxidation of Np in Anion Feed Solution

\begin{tabular}{|c|c|c|c|c|}
\hline & $\begin{array}{c}\text { ADS } \\
\text { ID }\end{array}$ & $\begin{array}{l}\text { Age } \\
\text { days }\end{array}$ & $\begin{array}{c}\mathrm{Np}(\mathrm{V}) \\
\%\end{array}$ & $\begin{array}{l}\mathrm{Np} \\
\mathrm{g} / \mathrm{l}\end{array}$ \\
\hline Cr234 Feed A & $3-189516$ & 2 & $3.60 \%$ & 3.167 \\
\hline 8M HNO3 & & 3 & $<0.16 \%$ & \\
\hline $0.06 \mathrm{M}$ excess FS & & 4 & $0.18 \%$ & \\
\hline $0 \mathrm{M}$ hydrazine & & 5 & $0.19 \%$ & \\
\hline Cr234 Feed B & 3-189517 & 2 & $5.40 \%$ & 3.103 \\
\hline 8M HNO3 & & 3 & $1.11 \%$ & \\
\hline $0.06 \mathrm{M}$ excess FS & & 4 & $1.43 \%$ & \\
\hline $0.02 \mathrm{M}$ hydrazine & & 5 & $3.68 \%$ & \\
\hline Cr236 Feed A & 3-190224 & 0.5 & ND & 3.167 \\
\hline 8M HNO3 & & 1.5 & ND & \\
\hline $0.06 \mathrm{M}$ excess FS & & 2.5 & ND & \\
\hline \multirow[t]{2}{*}{$0 \mathrm{M}$ hydrazine } & & 3.5 & ND & \\
\hline & & 4.5 & $0.29 \%$ & \\
\hline Cr236 Feed B & $3-190225$ & 0.5 & ND & 3.103 \\
\hline 8M HNO3 & & 1.5 & ND & \\
\hline $0.06 \mathrm{M}$ excess FS & & 2.5 & ND & \\
\hline \multirow[t]{2}{*}{$0.02 \mathrm{M}$ hydrazine } & & 3.5 & ND & \\
\hline & & 4.5 & $0.29 \%$ & \\
\hline Cr237 Feed & 3-190557 & 1 & $2.91 \%$ & 4.983 \\
\hline $\begin{array}{c}\text { Cr236 Feed C } \\
\text { undiluted } 8.5\end{array}$ & $3-190555$ & na & $98.20 \%$ & 19.191 \\
\hline Cr236 Feed D & $3-190556$ & 1 & $42.80 \%$ & 0.640 \\
\hline 8.5 added to $8 \mathrm{M} \mathrm{HNO} 3$ & no Fs, no N2H4 & & & \\
\hline
\end{tabular}

Hydrazine: One of the primary goals of this study was to determine the necessary concentrations of $\mathrm{N}_{2} \mathrm{H}_{4}$ in the anion process streams to allow for efficient operation of the process and yet minimize the need for DSA controls related to hydrazoic acid formation. Criteria were suggested that in both the feed and product solutions $\mathrm{Np}(\mathrm{IV})$ should be stable from significant oxidation for 4 days. Significant oxidation was considered be greater than 0.5 percent. There was interest in considering longer periods of time, but testing becomes increasingly time consuming when periods of 1 or 2 weeks are studied. Processing delays of one week are not considered routine due to a significant penalty for the lost production time. In the baseline flowsheet, $\mathrm{N}_{2} \mathrm{H}_{4}$ is used in the anion feed, in the wash stream and in the elution acid. In a parallel study, Askew (13)

showed that anion exchange resin under Np processing conditions did not concentrate hydrazoic acid.

Hydrazine in the feed solution: The concentration of $\mathrm{N}_{2} \mathrm{H}_{4}$ in the feed solution was varied from 0 to 0.1M. In runs $\mathrm{Cr} 221-\mathrm{Cr} 224$, which had the highest $\mathrm{N}_{2} \mathrm{H}_{4}$ concentrations, the losses were uniformly low at less than $0.6 \%$. Runs $\mathrm{Cr} 222$ and $\mathrm{Cr} 224$ were allowed to age for 5 and 7 days respectively prior to loading as those solutions were recycled from break-through loading runs and had been chemically adjusted for the first column run. Inconsistent results were obtained when $\mathrm{N}_{2} \mathrm{H}_{4}$ was not used but the $\mathrm{Np}$ loading varied considerably.

Experiments $\mathrm{Cr} 234$ and $\mathrm{Cr} 236$ were test feed samples where the $\mathrm{Np}$ was added to a matrix of $\mathrm{HNO}_{3}$, FS and $\mathrm{N}_{2} \mathrm{H}_{4}$ and the percent $\mathrm{Np}^{5+}$ was determined over time. In each experiment, samples were prepared that only differed by the presence of $\mathrm{N}_{2} \mathrm{H}_{4}$. The results from these tests are shown in Table V. Experiment $\mathrm{Cr} 234$ gave erratic results that were attributed to lab error. When repeated as $\mathrm{Cr} 236 \mathrm{~A} \& \mathrm{~B}$, the results were consistent and indicated that $\mathrm{N}_{2} \mathrm{H}_{4}$ was not necessary to achieve low losses. In $\mathrm{Cr} 236 \mathrm{~A}$ and $\mathrm{Cr} 236 \mathrm{~B}$, no $\mathrm{Np}^{5+}$ was detected until the samples were 4.5 days old and at that time the $\mathrm{Np}^{5+}$ consisted of only $0.29 \%$. No difference was detected in this experiment based on the presence or absence of $\mathrm{N}_{2} \mathrm{H}_{4}$.

Other samples were also prepared as part of $\mathrm{Cr} 236$ and the results are also shown in Table V. Unaltered Tank 8.5 sample from H-Canyon in August 2002 and Tank 8.5 sample diluted (1:30) with $8 \mathrm{M} \mathrm{HNO}_{3}$ were tested for $\mathrm{Np}^{5+}$. As expected, essentially all the $\mathrm{Np}$ in the unaltered 8.5 sample was $\mathrm{Np}^{5+}$. However the sample that consisted of an $8 \mathrm{M} \mathrm{HNO}_{3}$ dilution of tank 8.5 without any valence chemicals was only $42.8 \% \mathrm{~Np}^{5+}$ the next day. Although no data exists, the manufacturer of the TEVA column believes that $\mathrm{Np}^{6+}$ behaves like $\mathrm{UO}_{2}{ }^{2+}$ in $\mathrm{HNO}_{3}$ and should end up being counted as $\mathrm{Np}^{5+}$ by this test procedure. If the result of the $\mathrm{Np}^{5+}$ test actually represents total $\mathrm{Np}^{5+}+\mathrm{Np}^{6+}$ then $57+\%$ of the $\mathrm{Np}^{5+}$ was reduced to $\mathrm{Np}^{4+}$. The only mechanism recognized is disproportionation, but that should produce just as much $\mathrm{Np}^{6+}$ as $\mathrm{Np}^{4+}$. Although our understanding of the chemistry involved is not complete, it is not surprising that nitrate complexation of $\mathrm{Np}^{4+}$ might shift the equilibria between the three valence states to favor $\mathrm{Np}^{4+}$. The effect of time on this equilibrium was not tested, 
but probably a large percentage of $\mathrm{Np}$ could be recovered without either FS or $\mathrm{N}_{2} \mathrm{H}_{4}$ addition. Over time, radiation dose to the $\mathrm{HNO}_{3}$ is expected to produce nitrite that should increase the fraction of $\mathrm{Np}^{5+}$ present. It could also reduce the $\mathrm{Np}^{6+}$ to $\mathrm{Np}^{5+}$.

The last feed sample tested for $\mathrm{Np}^{5+}$ was the actual feed to $\mathrm{Cr} 237$ a day after FS addition (but without $\mathrm{N}_{2} \mathrm{H}_{4}$ ). In this case $2.91 \%$ was reported as $\mathrm{Np}^{5+}$ and when the column was run on the fifth day, total losses were measured at $2.5 \%$. This result suggests that most of the losses were due to improper valence one day after preparation. Unfortunately no raffinate spectra were obtained from this column run. That would have been a way to confirm that the cause of the high losses was due to $\mathrm{Np}^{5+}$ and not some other loading problem.

Experiment $\mathrm{Cr} 238$ was intended to validate the up-load down-elute column operation with feed prepared from tank 8.5 samples (just like $\mathrm{Cr} 236$ and $\mathrm{Cr} 237$ ). The results from $\mathrm{Cr} 237$ were not yet available when Cr238 was run and the spectrometer was not operating. The losses from this run were slightly less than those observed in $\mathrm{Cr} 237$, but no data were obtained to suggest the cause. The high losses may have been caused by the slow oxidation of $\mathrm{Np}^{4+}$ to $\mathrm{Np}^{5+}$ although other causes cannot be ruled out. The end result was that in 3 of the 4 tests unsatisfactory results with regard to losses were obtained when non- $\mathrm{N}_{2} \mathrm{H}_{4}$ feed was aged for 5 days. Based on the results of these tests, $\mathrm{N}_{2} \mathrm{H}_{4}$ appears to be necessary in anion feed solution to prevent $\mathrm{Np}^{4+}$ oxidation. If $\mathrm{N}_{2} \mathrm{H}_{4}$ is removed from the valence adjustment step, the possibility of increased losses to the raffinate of up to $3 \%$ should be anticipated.

Hydrazine in the wash solution: In the initial portion of this experimental program, there was concern that $\mathrm{Pu}^{238}$ needed to be removed to satisfy shipping/storage concerns of the customer. Initially efforts were expended to increase the DF for Pu by lowering the $\mathrm{HNO}_{3}$ concentration in the feed and wash and increasing the effectiveness of FS reduction of Pu. Increasing the FS concentration in the feed and the "partition wash" was expected to increase Pu removal. Increasing the $\mathrm{N}_{2} \mathrm{H}_{4}$ concentration in the feed and the wash was expected to reduce the $\mathrm{HNO}_{2}$ concentration and to protect the $\mathrm{Fe}^{2+}$ from oxidation. After several experiments it became apparent that the success of preventing Pu from absorbing onto the resin depended on processing the entire feed solution very promptly. With the expected large heel volumes in the feed tanks, it became apparent that obtaining a good DF for Pu during the loading cycle was not very practical with the expected equipment limitations in HB-Line. The desired high production rate would also have to suffer significantly to improve the Pu removal. Results for the DF obtained for $\mathrm{Pu}$ and for $\mathrm{Pa}$ are noted in this report, but efforts to provide a Pu removal ability to the process were abandoned in the middle of the study. Based on the time it took for significant $\mathrm{Np}^{5+}$ to form in $8 \mathrm{M} \mathrm{HNO}_{3}, \mathrm{~N}_{2} \mathrm{H}_{4}$ was then dropped from the wash solution. This change did not appear to affect losses during washing. The decon wash step remains recommended for the proposed flowsheet as it lowers the level of impurities in the hearts cut for a very modest volume and time investment and is needed to empty the feed line and loaded portion of the resin bed of residual $\mathrm{Np}$ feed solution. If no wash were performed at all, losses to the heads cut would be expected to rise significantly

Hydrazine in the elution acid: $\mathrm{Np}^{5+}$ has been identified in the literature as a cause for high precipitation losses and ascorbic acid is added in the precipitator feed adjustment to scavenge whatever $\mathrm{Np}^{5+}$ does form. The amount of ascorbic acid proposed in the baseline flowsheet amounts to $0.03 \mathrm{M}$ excess (assuming no $\mathrm{Np}^{5+}$ is formed). The ascorbic acid reduction of $\mathrm{Np}$ depends on $\left[\mathrm{HNO}_{3}\right]$, temperature, and on the absence of $\mathrm{HNO}_{2}$ (which will rapidly oxidize the ascorbic acid). Ascorbic acid in Pu or $\mathrm{Np}$ solutions forms tars and black solids upon oxidation that cause operational problems in the process. Porter (14) tested ascorbic acid in the range of 0.03 to $0.06 \mathrm{M}$. In those tests he recommended $0.05 \mathrm{M} \mathrm{N}_{2} \mathrm{H}_{4}$ in the elution acid and found that this concentration was sufficient to maintain the $\mathrm{Np}^{4+}$ for two weeks after elution. For these reasons the $\mathrm{N}_{2} \mathrm{H}_{4}$ has been found to be required in the valence adjustment step for precipitation. The purpose of $\mathrm{N}_{2} \mathrm{H}_{4}$ in the elution acid is to

Table VI. Oxidation of Np in Anion Product Solution

\begin{tabular}{|c|c|c|c|c|c|c|c|}
\hline Run ID & $\alpha \% \mathrm{~Np}$ & $\mathrm{ppm} \mathrm{Pu}$ & ppm Pu238 & {$\left[\mathrm{N}_{2} \mathrm{H}_{4}\right]$} & $\% \mathrm{~Np}(\mathrm{~V})$ & $\begin{array}{c}\text { Days after } \\
\text { Elution }\end{array}$ & \\
\hline Cr230 & 85 & 779 & 3 & 0 & $\begin{array}{l}\sim 100 \\
\end{array}$ & $14-21$ & 1 \\
\hline \multirow[t]{2}{*}{$\mathrm{Cr} 231$} & 2 & 3064 & 1434 & 0 & 1.29 & 1 & \\
\hline & & & & & $\sim 100$ & 7 & 2 \\
\hline \multirow[t]{2}{*}{$\mathrm{Cr} 232$} & 2 & 2931 & 1371 & 0.01 & 6.39 & 1 & \\
\hline & & & & & 10.9 & 5 & \\
\hline $\mathrm{Cr} 233$ & 4 & 3363 & 1002 & 0.05 & 0.36 & 3 & \\
\hline
\end{tabular}
maintain the Np product solution as $\mathrm{Np}^{4+}$ until it can be precipitated as $\mathrm{Np}\left(\mathrm{C}_{2} \mathrm{O}_{4}\right)_{2}$. This $\mathrm{N}_{2} \mathrm{H}_{4}$ minimizes the amount of ascorbic acid required and avoids the problems associated with the larger amount of ascorbic acid that would be required if the $\mathrm{Np}$ were allowed 
Figure 6. Oxidation of Diluted Np Hearts over Time 900-1000nm

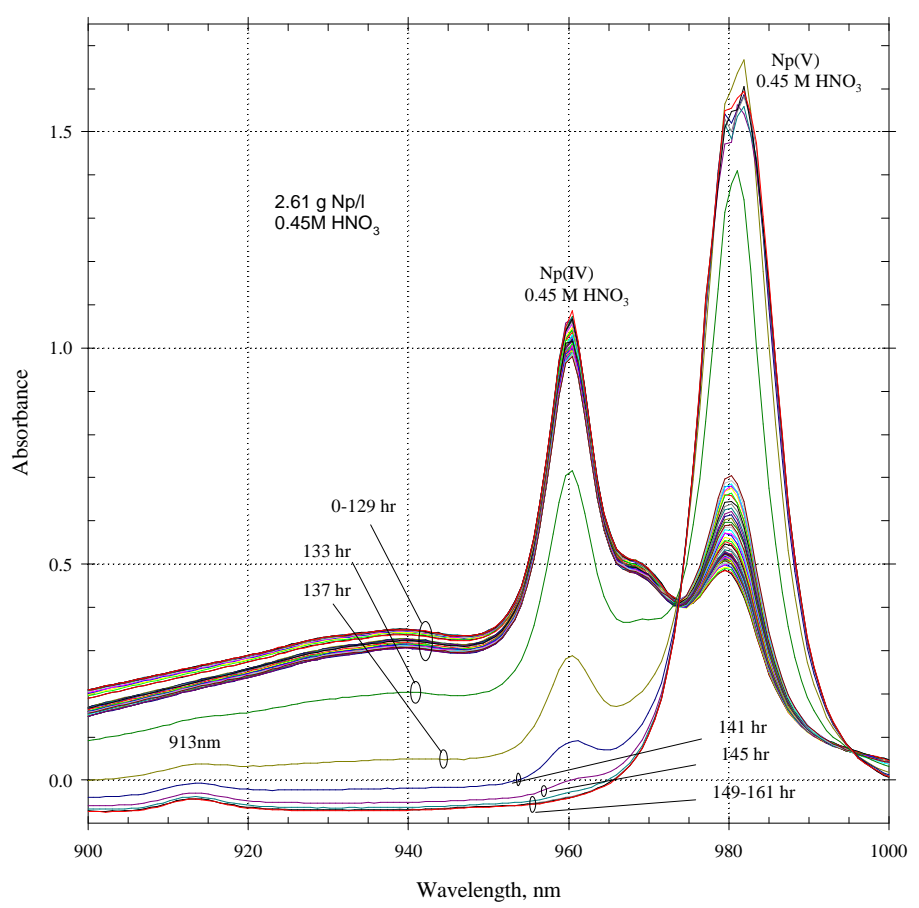

Figure 7. Oxidation of Diluted Np Hearts over Time 580-750nm

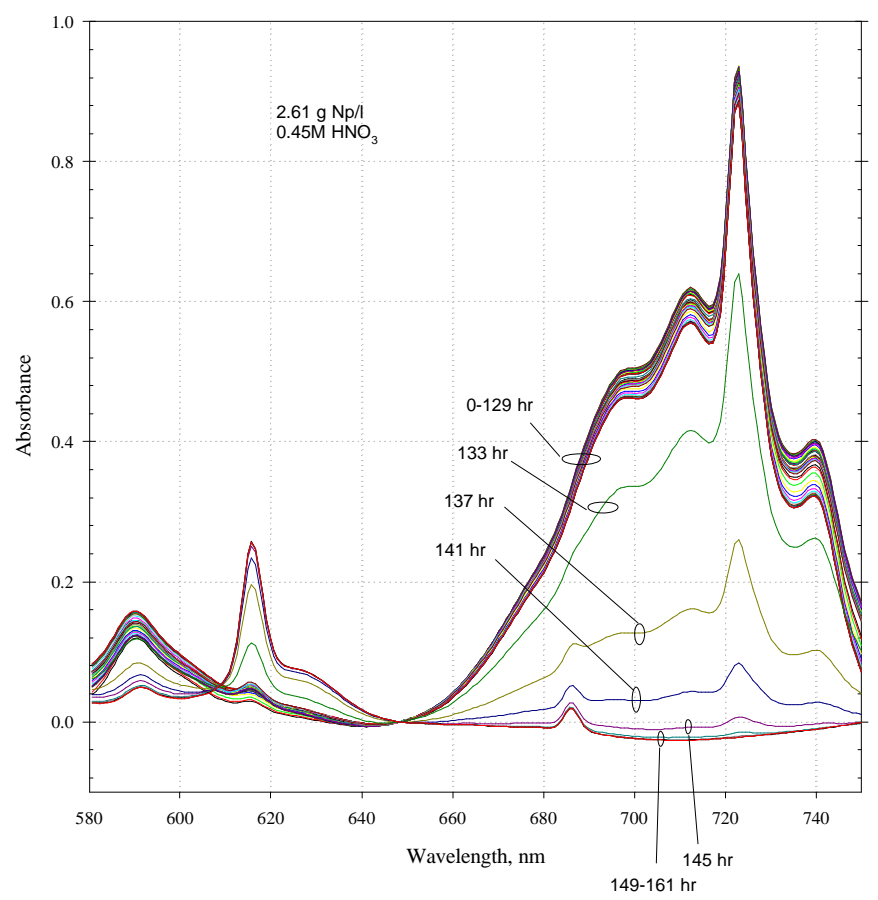

to oxidize. The question posed for the current study was could the amount of $\mathrm{N}_{2} \mathrm{H}_{4}$ be reduced. Table VI summarizes the results obtained on the stability of $\mathrm{Np}^{4+}$ in anion exchange product solution. Both spectral observations and the $\mathrm{Np}^{5+}$ analytical test results are included. Without $\mathrm{N}_{2} \mathrm{H}_{4}$ the $\mathrm{Np}^{4+}$ appeared to oxidize completely over 1-2 weeks. This behavior was observed for solutions that contained both relatively low and high levels of $\mathrm{Pu}^{238}$. Studies with diluted hearts samples showed a steady oxidation rate until a point was reached at which the entire sample converted to $\mathrm{Np}^{5+}$. Figures 6 and 7 show detailed spectra of this oxidation. If the spectral changes are presumed linear (not necessarily a good assumption), it appears that roughly $10-20 \%$ of the diluted sample oxidizes over the first $129 \mathrm{hr}$ after elution. Over the next 16 hours it appears that essentially all the $\mathrm{Np}^{4+}$ oxidizes to $\mathrm{Np}^{5+}$. This delay effect may have been due to residual sulfamate from the feed solution that was retained by the anion exchange resin. Sulfate on the order of $0.004 \mathrm{M}$ was measured in a grab sample late in the heads cut of $\mathrm{Cr} 233$. The time scale of the accelerated oxidation of this diluted sample has limited meaning to the situation in HB-Line.

Figure 8 shows similar data to that in Figures 6 and 7, but in this case it shows the oxidation as it occurs in undiluted "post-Hearts" samples from runs $\mathrm{Cr} 230$ and $\mathrm{Cr} 231$. Interestingly, Cr230 had much less $\mathrm{Pu}^{238}$ contamination than $\mathrm{Cr} 231$ and total alpha activity (and thus the alpha dose) was almost 100 times less. Still the oxidation rates are very similar and after three weeks the Cr230PC2 solution was completely oxidized to $\mathrm{Np}^{5+}$. No attempt has been made to confirm the $\mathrm{Cr} 230$ result, but if true, it suggests that chemical oxidation is controlling. However, this author is somewhat skeptical of that result without further confirmation.

Although the mechanism is not completely understood, it appears that the basic oxidation rate is too 
Figure 8. Oxidation of $\mathrm{Np}^{4+}$ to $\mathrm{Np}^{5+}$ in Weak $\mathrm{HNO}_{3}$

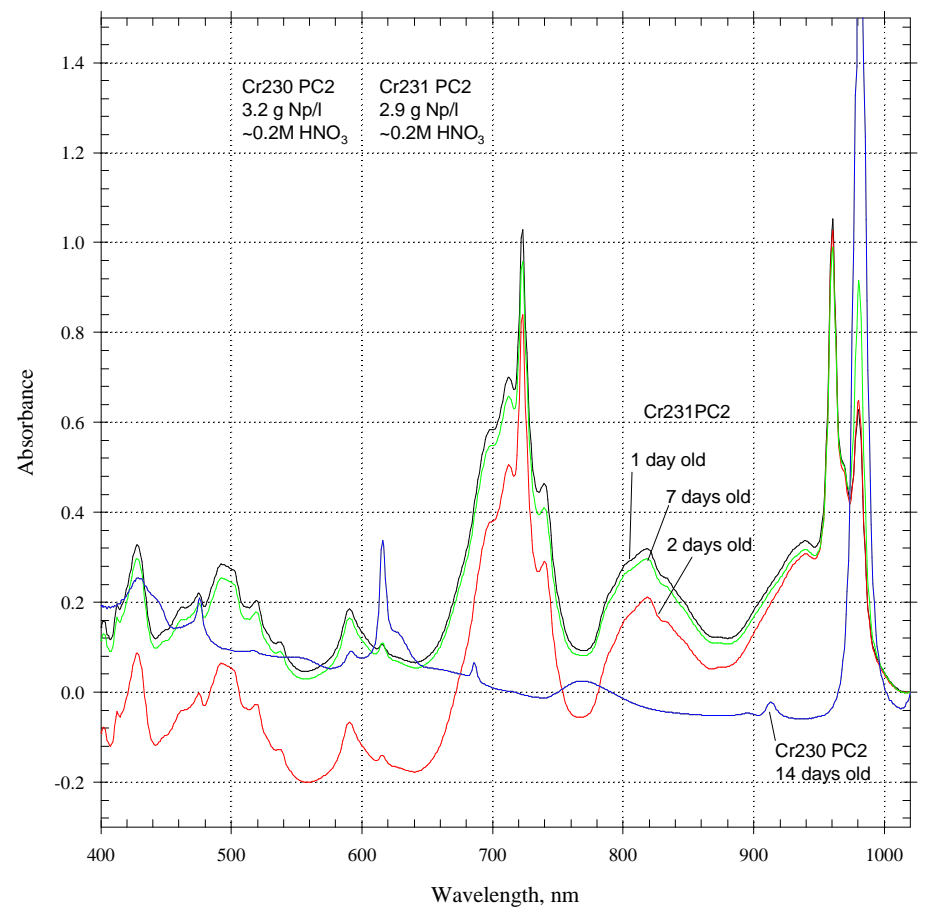

rapid to wait to add $\mathrm{N}_{2} \mathrm{H}_{4}$ after elution. When $0.01 \mathrm{M} \mathrm{N}_{2} \mathrm{H}_{4}$ was tested, six percent oxidized in the first day compared with $0.36 \%$ total after four days when $0.05 \mathrm{M}$ $\mathrm{N}_{2} \mathrm{H}_{4}$ was used in the elution acid. Ultimately it was decided that the objective of reducing the $\mathrm{N}_{2} \mathrm{H}_{4}$ in the elution acid stream was of limited value. As a result, the conclusion was reached to leave the elution acid stream unchanged in composition at $0.17 \mathrm{M} \mathrm{HNO}_{3}$ and $0.05 \mathrm{M} \mathrm{N}_{2} \mathrm{H}_{4}$. The $\mathrm{Np}^{4+}$ in this product solution should be stable for more than three days with minimal oxidation. The addition of $0.03 \mathrm{M}$ ascorbic acid in the subsequent precipitation feed adjustment step should be effective at reducing the minor amounts of $\mathrm{Np}^{5+}$ that form. Higher concentrations of ascorbic acid should not be necessary unless significant processing delays are encountered.

Pu and Pa Decontamination: The column loading and wash conditions and the resulting DFs for Pu and $\mathrm{Pa}$ are tabulated in Table VII. DFs for $\mathrm{Pu}$ as high as 6.8 were measured when favorable conditions for $\mathrm{Pu}^{3+}$ stability were provided and 3 to $6 \mathrm{BV}$ of reductive wash was used. However it was recognized that due to equipment limitations it would be difficult to achieve a DF of better than 2 to 3 in the plant process. Large tank heels would limit the ability to process the adjusted feed solution promptly. Aged feed would build up the amount of $\mathrm{Fe}^{3+}$ and $\mathrm{SO}_{4}{ }^{2-}$ and require extra $\mathrm{FS}$ addition. Significant reductive wash volume would also be required. As a result the investigation of Pu rejection was abandoned.

$\mathrm{Pa} \mathrm{DF}$ results have some value due to radiation dose issues. In theory, one of the primary reasons anion exchange is performed is to lower the $\mathrm{Pa}^{233}$ content of the $\mathrm{Np}$ and reduce radiation dose to personnel. In practice, the Pa chemistry is fairly complex and the analytical results observed in this study were very variable. While DFs of greater than 20 were observed on several occasions, it appears that those high DFs were obtained only when significant reductive washing was being performed. When a $3 \mathrm{BV}$ decon wash was performed, a realistic expectation for the Pa DF appears to be in the 2.5 to 4 range. This still represents a Pa removal of 60 to $80 \%$. Reduction of the wash volume can be expected to further reduce the Pa rejection. It is likely that the valence state of $\mathrm{Pa}$ greatly affects the ability of the anion process to reject $\mathrm{Pa}$ to the raffinate stream, but no special effort was made to study this issue.

Uncertainties: As previously stated, instantaneous flowrates occasionally varied widely form the targeted value, but adjustments were quickly made to keep the average flowrate within $15 \%$ of the targeted value. Because resin loading was found to be only a weak function of flowrate in the earlier Pu study (5) the flowrate uncertainty probably contributes $<1 \%$ to the uncertainty in the loading results.

Measuring the resin bed depth to determine the volume of resin in the column is a relatively accurate measurement, but the resin beds pack into the bed unevenly and settle during the initial use. This uncertainty is estimated at $\sim 2 \%$ based on observations of settling as the resin columns are loaded. However additional resin was added during column setup to keep the resin volume at its targeted value. This adjustment should bias the amount of resin loaded towards a higher value and likewise bias the resin loading values upward over what would be observed if such care were not taken. As several runs were made with the same resin column, this uncertainty does not contribute to the variation in reproducibility between successive runs that use the same resin column. 
Analytical measurement uncertainty is generally dominated by dilution errors. Typically, dilution error is estimated as $\sim 3 \%$ for this work due to the equipment. Operator errors could easily cause a $30 \%$ or more error on an individual sample, but those errors would normally be recognized due to inconsistency and are rechecked.

A material balance was calculated for each run by taking the solution volumes and the analytical results from the feed, product and waste streams. Most column runs had an overall material balance uncertainty of $<4 \%$ for $\mathrm{Np}^{237}$. These results support the viewpoint that routine analytical results have a precision of $\sim 4 \%$ for $\mathrm{Np}^{237}$. Poor material balances were generally seen for $\mathrm{Pa}^{233}$. Solutions should have had been at secular equilibria between $\mathrm{Np}^{237}$ and $\mathrm{Pa}^{233}\left(\mathrm{~Np}^{237}\right.$ and $\mathrm{Pa}^{233}$ activities should be equal) often had 20-50\% less $\mathrm{Pa}^{233}$. $\mathrm{Pa}^{233}$ readily hydrolyzes and sticks to various surfaces even from 1-8 $\mathrm{M} \mathrm{HNO}_{3}$. No correction was made for $\mathrm{Pa}^{233}$ decay or ingrowth between anion exchange separation or ingrowth and gamma counting. In most cases those analyses were performed within two to four days after separation. A four day delay in counting would amount to $\sim 10 \%$ ingrowth of $\mathrm{Pa}^{233}$.

\section{Conclusions:}

A series of anion exchange runs has been performed in an attempt to define requirements for operating the process equipment in HB-Line. This work has generally confirmed the conditions described in the design flowsheet. Efforts to demonstrate a reduction in the amount of $\mathrm{N}_{2} \mathrm{H}_{4}$ required have generally not been successful based on the criteria provided. Elimination of $\mathrm{N}_{2} \mathrm{H}_{4}$ in the feed solution appears to leave the Np susceptible to limited oxidation over a time scale of days, however not all the experimental data was consistent. Five days after valence adjustment, experimental losses ranged from 0.3 to 3 percent of the $\mathrm{Np}$. Oxidation of $\mathrm{Np}$ in the anion product stream appears to occur fairly rapidly in the absence of $\mathrm{N}_{2} \mathrm{H}_{4}$. Elimination of $\mathrm{N}_{2} \mathrm{H}_{4}$ from the elution acid stream would therefore require a large increase in the amount of ascorbic acid required for precipitation.

Resin loading of $50 \mathrm{~g} \mathrm{~Np} / \mathrm{l}$ of resin was observed with losses of less than 0.5 percent. In a single upflow-load downflow-elute experiment a hearts cut of $40 \mathrm{~g} \mathrm{~Np} / \mathrm{l}$ was collected with losses to heads and tails cuts of $7 \%$. The loading results appear consistent with the desire to load $2 \mathrm{~kg}$ of Np on a 45 liter resin column. The elution result indicates that the goal of a $50 \mathrm{~g} / \mathrm{l}$ hearts cut should be achievable with additional losses to heads and tails cuts. 
WSRC-TR-2003-00111, Rev 0

Table VII. Summary of Pu and Pa DF Behavior

\begin{tabular}{|c|c|c|c|c|c|c|c|}
\hline & $\begin{array}{l}\text { Loading } \\
\text { Conditions }\end{array}$ & Washing & $\begin{array}{l}\text { Loading } \\
\text { Losses, \% }\end{array}$ & $\begin{array}{l}\text { Washing } \\
\text { Losses, \% }\end{array}$ & $\mathrm{Pu} \mathrm{DF}$ & $\mathrm{Pa} \mathrm{DF}$ & Comments \\
\hline \multirow[t]{3}{*}{$\mathrm{Cr} 221$} & $0.096 \mathrm{M} \mathrm{FS}$ & $3 \mathrm{BV}$ & na & na & 2.5 & 5.1 & $65 \%$ APHA Np \\
\hline & $0.05 \mathrm{M} \mathrm{N} 2 \mathrm{H} 4$ & $0.05 \mathrm{M} \mathrm{N} 2 \mathrm{H} 4$ & & & & & \\
\hline & 6.4M HNO3 & 6.4M HNO3 & & & & & \\
\hline \multirow[t]{3}{*}{$\mathrm{Cr} 222$} & $0.096 \mathrm{M} \mathrm{FS}$ & $3 \mathrm{BV}$ & 0.2 & na & 2.5 & $8-15$ & Remaining Cr221 Feed \\
\hline & $0.05 \mathrm{M} \mathrm{N} 2 \mathrm{H} 4$ & $0.05 \mathrm{M} \mathrm{N} 2 \mathrm{H} 4$ & & & & & $48 \%$ APHA Np \\
\hline & 6.4M HNO3 & 6.4M HNO3 & & & & & \\
\hline \multirow[t]{3}{*}{$\mathrm{Cr} 223$} & $0.2 \mathrm{M} \mathrm{FS}$ & 6BV $0.2 \mathrm{M} F S$ & 0.2 & 0.4 & 4.3 & 27.3 & White Solids after FS \\
\hline & $0.10 \mathrm{M} \mathrm{N} 2 \mathrm{H} 4$ & $0.10 \mathrm{M}$ N2H4 & & & & & $15 \%$ APHA Np \\
\hline & 6.4M HNO3 & 6.4M HNO3 & & & & & \\
\hline \multirow[t]{3}{*}{$\mathrm{Cr} 224$} & $0.05 \mathrm{M} \mathrm{FS}$ & $3 \mathrm{BV} 0.2 \mathrm{M} \mathrm{FS}$ & 0.02 & 0.3 & 2 & 20 & Feed aged 1 week \\
\hline & $0.05 \mathrm{M} \mathrm{N} 2 \mathrm{H} 4$ & $0.05 \mathrm{M} \mathrm{N} 2 \mathrm{H} 4$ & & & & & No Pu rejection \\
\hline & 6.4M HNO3 & 6.4M HNO3 & & & & & $42 \%$ APHA Np \\
\hline \multirow[t]{3}{*}{$\mathrm{Cr} 225$} & $0.1 \mathrm{M} F S$ excess & 3BV 0.08MFS & 0.1 & 1.3 & 6.8 & 2.5 & Small breakthur wash \\
\hline & $0.02 \mathrm{M} \mathrm{N} 2 \mathrm{H} 4$ & $0.05 \mathrm{M} \mathrm{N} 2 \mathrm{H} 4$ & & & & & Reject Pu during load and Wash \\
\hline & $6.2 \mathrm{M} \mathrm{HNO} 3$ & 6.4M HNO3 & & & & & $52 \%$ APHA Np \\
\hline \multirow[t]{3}{*}{$\mathrm{Cr} 226$} & $0.082 \mathrm{M} F S$ excess & $3 \mathrm{BV}$ & 0.06 & na & 1.3 & 3.1 & Higher loading \\
\hline & $0.02 \mathrm{M} \mathrm{N} 2 \mathrm{H} 4$ & $0.05 \mathrm{M} \mathrm{N} 2 \mathrm{H} 4$ & & & & & \\
\hline & 7.6M HNO3 & 6.4M HNO3 & & & & & 78\% APHA Np \\
\hline \multirow[t]{3}{*}{$\mathrm{Cr} 227$} & $0.082 \mathrm{M}$ FS excess & $3 \mathrm{BV}$ & 1.5 & 1.3 & 0.9 & 7.6 & Small Breakthru during loading $N p(I V)$ \\
\hline & 4 days old & no N2H4 & & & & & EC2 from $\mathrm{Cr} 226$ no new FS \\
\hline & 7.4M HNO3 & 8M HNO3 & & & & & 73\% APHA Np \\
\hline \multirow[t]{3}{*}{$\mathrm{Cr} 228$} & $0.061 \mathrm{M} F S$ & $0 \mathrm{BV}$ & 0.1 & na & 1.7 & 2.1 & Washed with elution acid \\
\hline & $0.005 \mathrm{M} \mathrm{N} 2 \mathrm{H} 4$ & & & & & & \\
\hline & $6.4 \mathrm{M} \mathrm{HNO3}$ & & & & & & \\
\hline \multirow[t]{3}{*}{$\mathrm{Cr} 229$} & $0.047 \mathrm{M}$ FS excess & $6 \mathrm{BV}$ & 0.01 & 0.01 & 1 & 0.8 & Poor $\mathrm{Pu}$ and $\mathrm{Pa} \mathrm{DF}$ \\
\hline & $0.008 \mathrm{M} \mathrm{N} 2 \mathrm{H} 4$ & no N2H4 & & & & & $80 \%$ APHA Np \\
\hline & 6.6M HNO3 & 6.4M HNO3 & & & & & \\
\hline \multirow[t]{3}{*}{$\mathrm{Cr} 230$} & $0.025 \mathrm{M}$ FS excess & $3 \mathrm{BV}$ & 3.73 & na & 2.6 & 1.2 & Slight breakthru, too fast? \\
\hline & $0 \mathrm{M} \mathrm{N} 2 \mathrm{H} 4$ & no N2H4 & & & & & 779 ppm Pu239 \\
\hline & 5.7M HNO3 & 8M HNO3 & & & & & $85 \%$ APHA Np \\
\hline \multirow[t]{3}{*}{$\mathrm{Cr} 231$} & $0.044 \mathrm{M} F S$ & $3 \mathrm{BV}$ & 0.06 & 0.0033 & 0.9 & 2.5 & 1434 ppm Pu238, 3064 ppm Pu238 \\
\hline & 0M N2H4 & no N2H4 & & & & & $2 \%$ APHA Np \\
\hline & 8.2M HNO3 & $8 \mathrm{M} \mathrm{HNO} 3$ & & & & & $1.29 \% \mathrm{~Np}(\mathrm{~V})$ in Product after 1 day \\
\hline \multirow[t]{3}{*}{$\mathrm{Cr} 232$} & $0.051 \mathrm{M}$ FS excess & $3 \mathrm{BV}$ & 0.06 & 0.06 & 1 & 1 & Poor Pa DF? \\
\hline & 0M N2H4 & no N2H4 & & & & & 2931 ppm Pu, 1371 ppm Pu238 \\
\hline & 8M HNO3 & 8M HNO3 & & & & & $2 \%$ APHA Np, $6.38 \% \mathrm{~Np}(\mathrm{~V})$ after 1 day \\
\hline \multirow[t]{3}{*}{$\mathrm{Cr} 233$} & $0.041 \mathrm{M}$ FS excess & $3 \mathrm{BV}$ & 14.6 & 1 & 3.1 & 3.7 & High Pu DF, Np(IV) in EC, rate? \\
\hline & $0.001 \mathrm{M} \mathrm{N} 2 \mathrm{H} 4$ & no N2H4 & & & & & 3363 ppm Pu, 1002 ppm Pu238 \\
\hline & 8.06M HNO3 & 8M HNO3 & & & & & 4\% APHA Np \\
\hline \multirow[t]{3}{*}{$\mathrm{Cr} 235$} & 0.04-0.075M FS excess & $3 \mathrm{BV}$ & $2 \%-4.6 \%$ & & 1 & 4 & Poor Pu matl balance \\
\hline & $0-0.02 \mathrm{M} \mathrm{N} 2 \mathrm{H} 4$ & no N2H4 & & & & & High Np losses, 2nd Feed btl? \\
\hline & 7-8M HNO3 & 8M HNO3 & & & & & $2 \%$ APHA Np \\
\hline \multirow[t]{3}{*}{ Cr237 } & $0.051 \mathrm{M}$ FS excess & $3 \mathrm{BV}$ & 1.87 & $0 . .5$ & 0.9 & 4 & Missing $\mathrm{Pa}$ \\
\hline & 0M N2H4 & no N2H4 & & & & & $2.9 \% \mathrm{~Np}(\mathrm{~V})$ after 1 day \\
\hline & 8M HNO3 & 8M HNO3 & & & & & $8 \%$ APHA Np \\
\hline \multirow[t]{3}{*}{$\mathrm{Cr} 238$} & $0.054 \mathrm{M}$ FS excess & $3 \mathrm{BV}$ & 1.36 & 0.44 & 1 & 3.4 & Upload-Downelute \\
\hline & OM N2H4 & no N2H4 & & & & & Missing Np \\
\hline & 8M HNO3 & 8M HNO3 & & & & & $8 \%$ APHA Np \\
\hline
\end{tabular}




\section{References}

1. S. F. Marsh, "Evaluation of a New Macroporous Polyvinylpyridine Resin for Processing Plutonium Using Nitrate Anion Exchange", LA-11490, Los Alamos National Laboratory, Los Alamos, NM (April 1989)

2. S. F. Marsh, "The Effects of In Situ Alpha-Particle Irradiations on Six Strong Base Anion Exchange Resins", LA-12055, Los Alamos National Laboratory, Los Alamos, NM (April, 1991)

3. S. F. Marsh, "The Effects of Ionizing Radiation on Reillex ${ }^{\mathrm{TM}} \mathrm{HPQ}$, A New Macroporous Polyvinylpyridine Resin and on Four Conventional Polystyrene Anion Exchange Resins", LA-11912, Los Alamos National Laboratory, Los Alamos, NM (Nov, 1990)

4. W. J. Crooks, E. A. Kyser, S. R. Walters, "Qualification of Reillex ${ }^{\mathrm{TM}} \mathrm{HPQ}$ Anion Exchange Resin for Use in SRS Processes", WSRC-TR-99-00317, Westinghouse Savannah River Company, Aiken, SC (March 10, 2000).

5. E. A. Kyser, "Plutonium Loading onto Reillex HPQ Anion Exchange Resin", WSRC-TR-2000-00372, Westinghouse Savannah River Company, Aiken, SC (Sept 26, 2000).

6. Drawing W720279 R0, "Savannah River Plant, Bldg 221H, Nept. 237, Plut. 239 Flow Diagram Process", (July 31,1981)

7. Drawing W719534 R6, “15” Diameter Column Arrgt. H363-110-5 \& 6”, (August 24, 1983)

8. M. L. Hyder (ed), Technical Manual 200-Area HM Process, DPSTM-200-HM, E. I. Du Pont de Nemours \& Co, Savannah River Laboratory, Aiken, SC, (July, 1977)

9. A. J. Hill, Savannah River Plant 200 Area Technical Manual, Part SP: Processing of $\mathrm{Np}^{237}$ and $\mathrm{Pu}^{238 \text {, }}$ DPSTM-200-SP, E. I. du Pont de Nemours and Company, Savannah River Laboratory, Aiken, SC (January 1963).

10. G. A. Burney, "Anion Exchange of Neptunium in Nitrate Solutions", DP-531, E. I. Du Pont de Nemours \& Co, Savannah River Laboratory, Aiken, SC, (Dec, 1960)

11. A. J. Johnson, G. A. Shepherd, "Spectrophotometry of Neptunium in Nitric Acid Solutions", RFP-958, Dow Chemical Co, Rocky Flats Division, Golden, CO (July 7, 1967).

12. H. A. Friedman, L. M. Toth, "Absorption Spectra of $\mathrm{Np}(\mathrm{III})$, (IV), (V), and (VI) in Nitric Acid Solution", J. Inorg. Nucl. Chem., 42(5), 1347-1349, (1980)

13. N. M. Askew, "Adsorption of Hydrazoic Acid on Reillex HPQ ${ }^{\mathrm{TM}}$ Anion Exchange Resin", WSRC-TR2003-00115, Westinghouse Savannah River Company, Aiken, SC (Feb 28, 2003).

14. J. A. Porter, "Precipitation of Neptunium Oxalate and Calcination to Neptunium Oxide", DP-591, E. I. Du Pont de Nemours \& Co, Savannah River Laboratory, Aiken, SC, (July, 1961) 